\title{
Microstructure Mixing Observations and Finescale Parameterizations in the Beaufort Sea
}

\author{
Elizabeth C. Fine, ${ }^{a}$ Matthew H. Alford, ${ }^{\mathrm{b}}$ Jennifer A. MacKinnon, ${ }^{\mathrm{b}}$ And John B. MicKetT ${ }^{\mathrm{c}}$ \\ ${ }^{a}$ Woods Hole Oceanographic Institution, Woods Hole, Massachusetts \\ ${ }^{\mathrm{b}}$ Scripps Institution of Oceanography, University of California, San Diego, La Jolla, California \\ ${ }^{\mathrm{c}}$ Applied Physics Laboratory, University of Washington, Seattle, Washington
}

(Manuscript received 20 September 2019, in final form 14 October 2020)

\begin{abstract}
In the Beaufort Sea in September of 2015, concurrent mooring and microstructure observations were used to assess dissipation rates in the vicinity of $72^{\circ} 35^{\prime} \mathrm{N}, 145^{\circ} 1^{\prime} \mathrm{W}$. Microstructure measurements from a free-falling profiler survey showed very low $\left[\odot\left(10^{-10}\right) \mathrm{W} \mathrm{kg}^{-1}\right]$ turbulent kinetic energy dissipation rates $\varepsilon$. A finescale parameterization based on both shear and strain measurements was applied to estimate the ratio of shear to strain $R_{\omega}$ and $\varepsilon$ at the mooring location, and a strain-based parameterization was applied to the microstructure survey (which occurred approximately $100 \mathrm{~km}$ away from the mooring site) for direct comparison with microstructure results. The finescale parameterization worked well, with discrepancies ranging from a factor of 1-2.5 depending on depth. The largest discrepancies occurred at depths with high shear. Mean $R_{\omega}$ was 17 , and $R_{\omega}$ showed high variability with values ranging from 3 to 50 over 8 days. Observed $\varepsilon$ was slightly elevated (factor of 2-3 compared with a later survey of 11 profiles taken over $3 \mathrm{~h}$ ) from 25 to $125 \mathrm{~m}$ following a wind event which occurred at the beginning of the mooring deployment, reaching a maximum of $\varepsilon=6 \times 10^{-10} \mathrm{~W} \mathrm{~kg}^{-1}$ at $30-\mathrm{m} \mathrm{depth}$. Velocity signals associated with near-inertial waves (NIWs) were observed at depths greater than $200 \mathrm{~m}$, where the Atlantic Water mass represents a reservoir of oceanic heat. However, no evidence of elevated $\varepsilon$ or heat fluxes was observed in association with NIWs at these depths in either the microstructure survey or the finescale parameterization estimates.
\end{abstract}

KEYWORDS: Ocean; Arctic; Internal waves; Turbulence; Diapycnal mixing

\section{Introduction}

Turbulent mixing in the western Arctic Ocean sets the vertical distribution of heat in the western Arctic and thus mediates the growth/melt cycles of sea ice (Aagaard et al. 1981; Timmermans et al. 2017). Thermohaline structure in the western Arctic is characterized by a double halocline stratification, allowing heat to be stored at depth. At the surface lies a layer of cool and freshwater associated with sea ice (Coachman and Barnes 1961; Jackson et al. 2010). Beneath the surface, Pacific Summer Water is formed due to summertime subduction of relatively warm Pacific-origin water and is found from approximately 30 to $100 \mathrm{~m}$ deep (Coachman and Barnes 1961; Timmermans et al. 2014). This water mass is separated from the deeper Atlantic Water by colder and saltier Pacific Winter Water that forms in the shelf seas surrounding the western Arctic (Pickart et al. 2005). The Atlantic Layer, which in the western Arctic is found between 200- and 800-m depth, contains enough heat to melt the entirety of the Arctic sea ice many times over if it were transported directly to the surface (Rudels et al. 2004), while the Pacific Summer Water heat content could melt approximately $1 \mathrm{~m}$ of surface sea ice (Timmermans et al. 2018).

Compared to midlatitude oceans, mixing rates tend to be low in the western Arctic, minimizing the influence of heat stored in deep temperature maximums on near-surface heat content and ocean-ice heat fluxes (Padman and Dillon 1987; Rainville and Winsor 2008; Fer 2009; Shaw et al. 2009; Toole et al. 2010; Jackson et al. 2010; Lincoln et al. 2016). In the

Corresponding author: Effie Fine, efine@whoi.edu midlatitude stratified ocean interior most mixing is driven by internal waves, which are primarily forced by the wind and the tides (Munk and Wunsch 1998). Turbulent mixing occurs due to wave-wave interactions that transfer energy to increasingly high wavenumbers leading to instabilities or due to direct breaking (Klymak et al. 2008; Alford and Gregg 2001). Thus, the degree of mixing from breaking internal waves is related to the spectral level of the wave field. While regional features of the internal wave field vary, throughout much of the global ocean the empirical Garrett-Munk (GM) spectrum is a reasonable approximation of both the overall internal wave energy and its frequency and wavenumber distribution (Garrett and Munk 1972, 1975; Cairns and Williams 1976; Polzin et al. 2014). However, in the western Arctic the energy content of the internal wave field has historically been an order of magnitude smaller than the Garrett-Munk spectrum, so that less energy is available to drive mixing than in the typical ocean environment (Levine et al. 1985). The presence of sea ice and weak Arctic tides tend to limit the energy available to the Arctic internal wave field, and the Arctic Ocean is also well north of the midlatitude storm track that is a hot spot of wind input to the internal wave field (Alford 2001).

A decline of sea ice area and volume and a corresponding increase of wind-driven momentum transfer into the western Arctic Ocean have been hypothesized to have significant implications for stratification and vertical heat transport (Rainville and Woodgate 2009; Dosser and Rainville 2016). If reduction of summer sea ice were to substantially increase the transfer of energy from the wind into the interior Arctic Ocean, this could result in increased dissipation at depth and more mixing of the deep ocean. Such mixing could transport heat from Atlantic Water upward, potentially creating a feedback 
loop as increased vertical heat fluxes accelerate sea ice melt. Some observations suggest an increase in internal wave energy in response to wind forcing in regions with reduced summer sea ice. For example, energetic internal waves have been observed in mooring data in the Chukchi Sea from July through September, when sea ice is near its seasonal minimum (Rainville and Woodgate 2009). An upward trend in nearinertial wave (NIW) amplitudes in the western Arctic has also been identified in Ice-Tethered Profiler (ITP) records from 2005 to 2014 (Dosser and Rainville 2016). Comparisons between ITPs in lower and higher ice concentrations demonstrate that more internal wave energy is found surrounding the ITPs in low sea ice concentration regions (Cole et al. 2018), and the same effect has been observed by moorings on the Beaufort slope (Martini et al. 2014). These observations suggest that as low sea ice conditions become more persistent throughout the summer Arctic, windforced NIWs provide a pathway for energy into the deep western Arctic.

In spite of observations of increased internal wave energy in response to surface forcing, observations in the western Arctic have not found a corresponding increase in the rate of dissipation of TKE $\varepsilon$ in the ocean interior in response to surface forcing. Indirect estimates of $\varepsilon$ compared across the last decades have not identified substantial increases in more recent years (Guthrie et al. 2013; Lique et al. 2014; Chanona et al. 2018; Chanona and Waterman 2020; Chanona 2020). Lincoln et al. (2016) directly measured microstructure shear following a storm that occurred over ice-free waters in the Beaufort Sea. While NIWs were observed, $\varepsilon$ and heat fluxes out of the Atlantic Water were not elevated beyond typical background rates. These observations suggest that even during large storms, wind energy transfer into the interior ocean may not cause a significant increase in local $\varepsilon$ and corresponding mixing in the Arctic Ocean's Atlantic halocline.

Due to the seasonal constraints of ship-based sampling in the Arctic, in situ microstructure measurements are scarce, making it difficult to determine whether mixing rates are changing on seasonal and interannual time scales. While process studies provide detailed descriptions of single events, methods that assess mixing on longer time scales are needed to place these descriptions in context. Finescale parameterizations infer mixing rate estimates from widely available (often autonomously collected) data, and have been used to make inferences about Arctic mixing over longer time scales (Guthrie et al. 2013; Lique et al. 2014; Chanona et al. 2018; Chanona 2020). These parameterizations rely on the assumption that the ocean's internal wave field is locally in steady state and that energy cascades from large vertical scales to dissipative scales via internal waves (Polzin et al. 2014). Provided these assumptions hold, $\varepsilon$ can be inferred from observations of strain and shear of the internal wave field at scales much larger than the scales of dissipation.

Finescale parameterizations have been applied to both CTD and velocity data in the global ocean, assuming a constant ratio of shear to strain where both quantities are not available (e.g., Whalen et al. 2012, 2015; Kunze 2003; Kunze et al. 2006; Waterhouse et al. 2014; Polzin et al. 2014; Kunze 2017). Generally, agreement between finescale parameterizations and direct microstructure measurements are robust to within a factor of 2-3 (Whalen et al.2015), although they may diverge in regions where mixing occurs due to processes other than a downscale energy cascade in internal waves [e.g., topographic mixing, convection, double diffusive convection; see Polzin et al. (2014) and Waterman et al. (2014)]. Many of these studies rely on measurements of only strain, so that a constant ratio of shear to strain is assumed to infer mixing. The resultant inferred mixing rates are very sensitive to the ratio assumed (Chinn et al. 2016).

At high latitudes, the assumptions that go into the finescale parameterization may not hold. Finescale parameterizations systematically overestimate turbulence at specific deep sites in the Southern Ocean (Waterman et al. 2014). However, a limited number of direct comparisons between finescale parameterizations and microstructure observations in the western Arctic show promising results (Guthrie et al. 2013). More comparisons are necessary to understand the opportunities afforded by existing autonomous sampling systems to estimate mixing rates over climatological time scales and to quantify biases that may arise in applying finescale parameterizations in an environment that is quite different from the low to midlatitude oceans.

In the current study, we present observations collected by microstructure profilers and by a mooring deployed in the Beaufort Sea in September of 2015. The mooring was deployed soon after a wind event that generated NIWs. These observations provide an opportunity to compare microstructure measurements with strain-based finescale parameterization estimates of mixing rates simultaneously in the same region. At the mooring location, strain and shear were concurrently measured, allowing for direct assessment of how the shear-tostrain ratio used in the finescale parameterization varied in time and in depth. A finescale parameterization applied to the mooring data also provides an estimate of the effect of the NIW event on mixing in the upper ocean.

In section 2 we describe the methods used for data collection and analysis. Section 3 presents the oceanographic context for the study. Section 4 presents the mooring and microstructure data and the results of finescale parameterizations, as well as estimates of diffusivity and heat flux. In section 5 we discuss the interpretation of the finescale parameterizations, the energetics of the NIW event, and implications for the observed turbulent mixing and heat fluxes.

\section{Methods}

\section{a. Observations}

Data were collected during a cruise on board the R/V Sikuliaq from 30 August to 26 September 2015. A mooring instrumented with four ADCPs and two McLane profilers was deployed at $72^{\circ} 35.646^{\prime} \mathrm{N}, 145^{\circ} 1.002^{\prime} \mathrm{W}$ from 1 to 19 September 2015 (yeardays 243-262) (Fig. 1). During this time period, five microstructure surveys were made in the Beaufort Sea using a custom-built microstructure profiler. Due to a moored profiler failure, the current study focuses on data collected during the first 8 days of the mooring deployment, yeardays 243-251, and 
a)
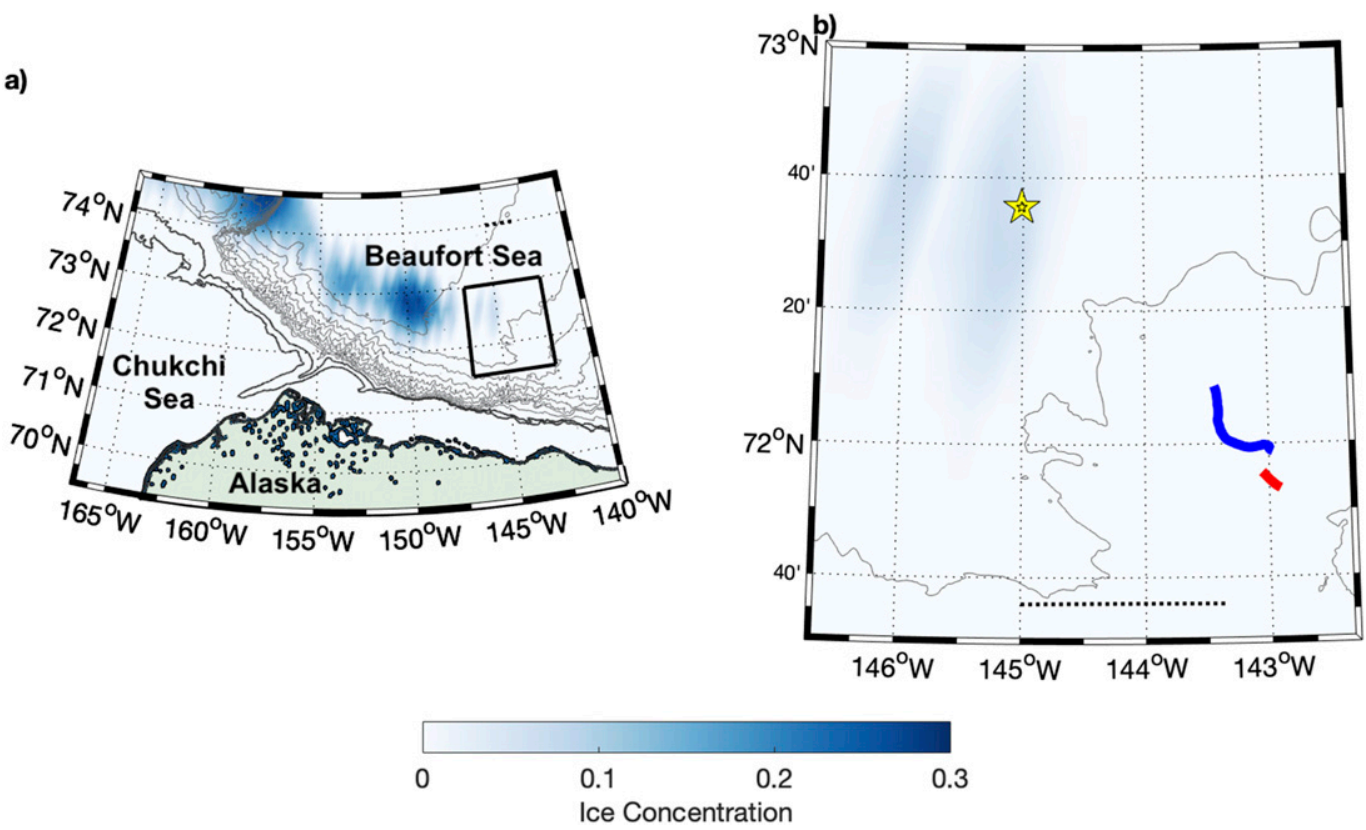

FIG. 1. Map of the study region. Colors show satellite observations of sea ice concentration from 30 Aug 2015 (Maslanik and Stroeve 1999). Gray lines show bathymetry, with heavy lines showing the 100- and 200-m isobaths and light contours at 400-m intervals from the surface to bottom. A dotted black line indicates the 50-km scale on each inset. (a) Regional map, where the study area is highlighted in a black box. (b) Study area. Mooring is shown as a yellow star. First and second microstructure survey locations are shown as blue and red lines, respectively. The bottom depth is $3466 \mathrm{~m}$ at the mooring location, $3133 \mathrm{~m}$ at the first MMP survey, and $3015 \mathrm{~m}$ at the second MMP survey.

the two microstructure profiler surveys conducted during this time frame (Fig. 1).

\section{1) MOORING DATA}

The instruments deployed on the mooring were an upwardlooking 300-kHz ADCP and a downward-looking 75-kHz ADCP both mounted at 42-m depth, a McLane Moored Profiler (Alford 2010) that sampled from 42 to $946 \mathrm{~m}$, and an upward-looking $300-\mathrm{kHz}$ ADCP mounted at 957-m depth. Unfortunately, the profiler stopped profiling during yearday 251,8 days into the deployment. The profiler collected hourly profiles of CTD data and velocity data, the latter with a precision of $\sim 3 \mathrm{~cm} \mathrm{~s}^{-1}$.

Temperature and salinity measurements from the moored profiler CTD are used to calculate gridded potential density data, which are sorted in depth to create stably stratified profiles prior to calculating isopycnal displacement $\zeta$ over $2-\mathrm{m}$ scales. Shear $\left(\mathbf{U}_{z 20}^{2}=u_{z 20}^{2}+v_{z 20}^{2}\right)$ is calculated by first differencing the moored profiler velocity over $20 \mathrm{~m}$ (a 20 -m scale for first-differencing is chosen to minimize the influence of highwavenumber noise in the Hovmöller plots). Similarly, the buoyancy frequency $N_{20 \mathrm{~m}}^{2}$ is also calculated as a first difference over $20 \mathrm{~m}$.

Beneath $300 \mathrm{~m}$ double diffusive layers and lateral intrusions frequently occur in the moored profiler record. These phenomena are ubiquitous in the western Arctic, although they are not the focus of the current study (Shibley et al. 2017; Bebieva and Timmermans 2017). We limit our analysis to depths above $300 \mathrm{~m}$, as below this range noise in shear and double diffusive layers complicate interpretation of the data.

\section{2) Microstructure DATA}

Microstructure measurements were collected using a Modular Microstructure Profiler (MMP), developed by M. C. Gregg at the Applied Physics Laboratory of the University of Washington and currently operated by the Multiscale Ocean Dynamics group at the Scripps Institution of Oceanography (Alford and Gregg 2001). The MMP is a loosely tethered profiler that falls at nominally $0.6 \mathrm{~m} \mathrm{~s}^{-1}$. It carries two custombuilt shear probes used to infer the dissipation rate of turbulent kinetic energy $\varepsilon$, an FP07 thermistor used to infer the dissipation rate of thermal variance $\chi$, a Seabird CTD, and an altimeter for near-bottom sampling. The turbulent kinetic energy dissipation rate $\varepsilon=(15 / 2) \nu \overline{(\partial \mathbf{u} / \partial z)^{2}}$ is calculated by iteratively fitting a Panchev curve to shear spectra measured by the shear probes and calculated over 2.5-s (1-2 $\mathrm{m})$ windows [indicated by the overbar of $\overline{(\partial \mathbf{u} / \partial z)^{2}}$ ]. The result is then binned to $0.25-\mathrm{m}$ bins to match the scale of the CTD data.

Direct measurements of $\varepsilon$ from the MMP were made during two surveys within $100 \mathrm{~km}$ of the mooring (Fig. 1). The first of these consisted of 53 profiles taken over $14.5 \mathrm{~h}$ on yearday 244 , while the second consisted of 11 profiles taken over $3 \mathrm{~h}$ on yearday 251 .

For a given $\varepsilon$, an upper bound for turbulent vertical density diffusivity $K_{\rho}$ may be calculated following Osborn (1980)

$$
K_{\rho} \leq \frac{\Gamma \varepsilon}{N^{2}}
$$

in which $\Gamma$ is a mixing efficiency generally taken to be 0.2 and $N^{2}$ is the time-averaged buoyancy frequency. Turbulent vertical 
thermal diffusivity is estimated assuming $K_{\rho}=K_{T}$, allowing for the calculation of a vertical heat flux $F_{H}=-\rho C_{p} K_{T} \theta_{z}$, with upward heat flux defined as positive.

\section{b. Data products}

Sea ice concentrations calculated from passive microwave brightness temperature data are used to characterize the study area at the start of a wind forcing event on 30 August 2015 (Maslanik and Stroeve 1999). Inverse model tidal velocities from the Arctic Ocean $5 \mathrm{~km}$ Inverse Model (AOTIM-5) are compared with mooring velocities to examine whether tidal forcing plays a significant role in the observations (Padman and Erofeeva 2004).

Hourly 10-m winds from the NCEP CFSv2 (Saha et al. 2010) are used to force a slab model. While meteorological wind data availability is limited in the Arctic, these reanalysis winds generate an Arctic surface wavefield that agrees reasonably well with available buoy data (Stopa et al. 2016) and show a wind event on yearday 241 that is consistent with a storm that occurred during the process cruise (Fig. 3).

\section{c. Finescale parameterization}

Following previous studies (Gregg 1989; Polzin et al. 1995; Kunze et al. 2006; Whalen et al. 2015), the rate of turbulent kinetic energy dissipation is calculated as

$$
\varepsilon=\varepsilon_{0} \frac{\overline{N^{2}}}{N_{0}^{2}} \frac{\left\langle U_{z}^{2}\right\rangle^{2}}{\left\langle U_{z \mathrm{GM}}^{2}\right\rangle^{2}} h_{1}\left(R_{\omega}\right) L(f, N) .
$$

Here, $\varepsilon_{0}=6.73 \times 10^{-10} \mathrm{~W} \mathrm{~kg}^{-1}, N_{0}=5.2 \times 10^{-3} \mathrm{rad} \mathrm{s}^{-1}, U_{z}$ is finescale vertical shear, and $\left\langle U_{z \mathrm{GM}}^{2}\right\rangle$ represents the variance of vertical shear from the Garret-Munk 1976 (GM76) model (Garrett and Munk 1972, 1975; Cairns and Williams 1976; Gregg and Kunze 1991). The scaling $h_{1}$ is defined as

$$
h_{1}\left(R_{\omega}\right)=\frac{3\left(R_{\omega}+1\right)}{2 \sqrt{2} R_{\omega} \sqrt{R_{\omega}-1}},
$$

and $R_{\omega}$ is the ratio of the variance of shear to strain,

$$
R_{\omega}=\frac{\left\langle U_{z}^{2}\right\rangle}{\overline{N^{2}}\left\langle\zeta_{z}^{2}\right\rangle}
$$

in which $\zeta$ represents isopycnal displacement. Isopycnal displacement is calculated by linear interpolation from the timemean density of each 2-m-depth bin. Strain is then calculated by first-differencing these isopycnal displacements from the 2-m binned data. The function $L(f, N)$ is defined as

$$
L(f, N)=\frac{f \cosh ^{-1}\left(\frac{\bar{N}}{f}\right)}{f_{30} \cosh ^{-1}\left(\frac{N_{0}}{f_{30}}\right)},
$$

in which $f$ is the Coriolis frequency and $f_{30}$ is the Coriolis frequency at $30^{\circ}$, and represents the latitudinal dependence of the internal wavefield (Gregg et al. 2003). This equation may be equivalently formulated with reference to strain as
TABLE 1. Results of a finescale parameterization using moored profiler shear and strain data. The range within a standard deviation of the mean is given in parentheses. Means of $\varepsilon$ are calculated geometrically.

\begin{tabular}{clc}
\hline \hline Depth range $(\mathrm{m})$ & \multicolumn{1}{c}{$\left\langle R_{\omega}\right\rangle$} & $\langle\varepsilon\rangle\left(\mathrm{W} \mathrm{kg}^{-1}\right)$ \\
\hline $75-150$ & $13(1-24)$ & $4 \times 10^{-10}\left(2-8 \times 10^{-10}\right)$ \\
$100-200$ & $26(16-36)$ & $7 \times 10^{-10}\left(4-11 \times 10^{-10}\right)$ \\
$150-250$ & $18(10-25)$ & $3 \times 10^{-10}\left(2-6 \times 10^{-10}\right)$ \\
$200-300$ & $11(4-18)$ & $2 \times 10^{-10}\left(1-3 \times 10^{-10}\right)$ \\
\hline
\end{tabular}

$$
\varepsilon=\varepsilon_{0} \frac{\overline{N^{2}}}{N_{0}^{2}} \frac{\left\langle\zeta_{z}^{2}\right\rangle^{2}}{\left\langle\zeta_{z \mathrm{GM}}^{2}\right\rangle^{2}} h_{2}\left(R_{\omega}\right) L(f, N),
$$

in which the scaling $h_{2}$ is defined as

$$
h_{2}\left(R_{\omega}\right)=\frac{R_{\omega}\left(R_{\omega}+1\right)}{6 \sqrt{2} \sqrt{R_{\omega}-1}} .
$$

To apply the finescale parameterization, we bin the data into four half-overlapping depth windows. The shallowest depth used for the analysis was $75 \mathrm{~m}$, as above this depth stratification varied rapidly with depth. Concurrent microstructure measurements also cover this depth range. The shallowest bin spanned from 75- to 150-m depth and was centered at $112.5 \mathrm{~m}$, and the next three were 100-m bins were centered at 150, 200, and $250 \mathrm{~m}$ (Table 1). For the MMP survey, the deepest bin was cut off at $284 \mathrm{~m}$ due to some profiles that did not reach $300 \mathrm{~m}$.

For the calculation of finescale shear, we divide the 2-m first difference of observed velocity from the moored profiler by $\bar{N}$, in which $\bar{N}$ is buoyancy frequency averaged in each depth range, following Kunze et al. (2006) (the high-wavenumber noise in 2-m shear is not of concern for this application, as a cutoff wavenumber removes its effect from the results). We detrend and window the scaled shear using a Hamming window. A Fourier transform is applied to find shear coefficients, and these are used to estimate shear spectra. These are corrected by a sinc ${ }^{2}$ function to account for the McLane profiler 2-m binning (Polzin et al. 2002). We average spectra together over 12-h intervals to minimize high-frequency noise and estimate variance by integrating spectra from the lowest wavenumber to a cutoff. The high-wavenumber cutoff of $0.05 \mathrm{cpm}$ (corresponding to a 20-m wavelength) is chosen to retain sufficient wavenumber range for the integration while avoiding small scales where white noise in velocity causes the shear spectra to rise linearly. Strain is similarly detrended, windowed with a Hamming window and Fourier transformed. Strain spectra are then averaged over the same 12-h intervals as shear and integrated to the same high-wavenumber cutoff of 0.05 cpm. Both strain and shear are additionally corrected by a sinc ${ }^{2}$ function to account for first-differencing.

As the 3-h duration of the second microstructure survey was much shorter than the 12-h intervals used to average shear and strain spectra, we only apply the finescale parameterization to the first microstructure survey. The moored profiler measured both density and velocity, allowing for direct calculation of the shear-to-strain ratio $R_{\omega}$. During the microstructure profiler 

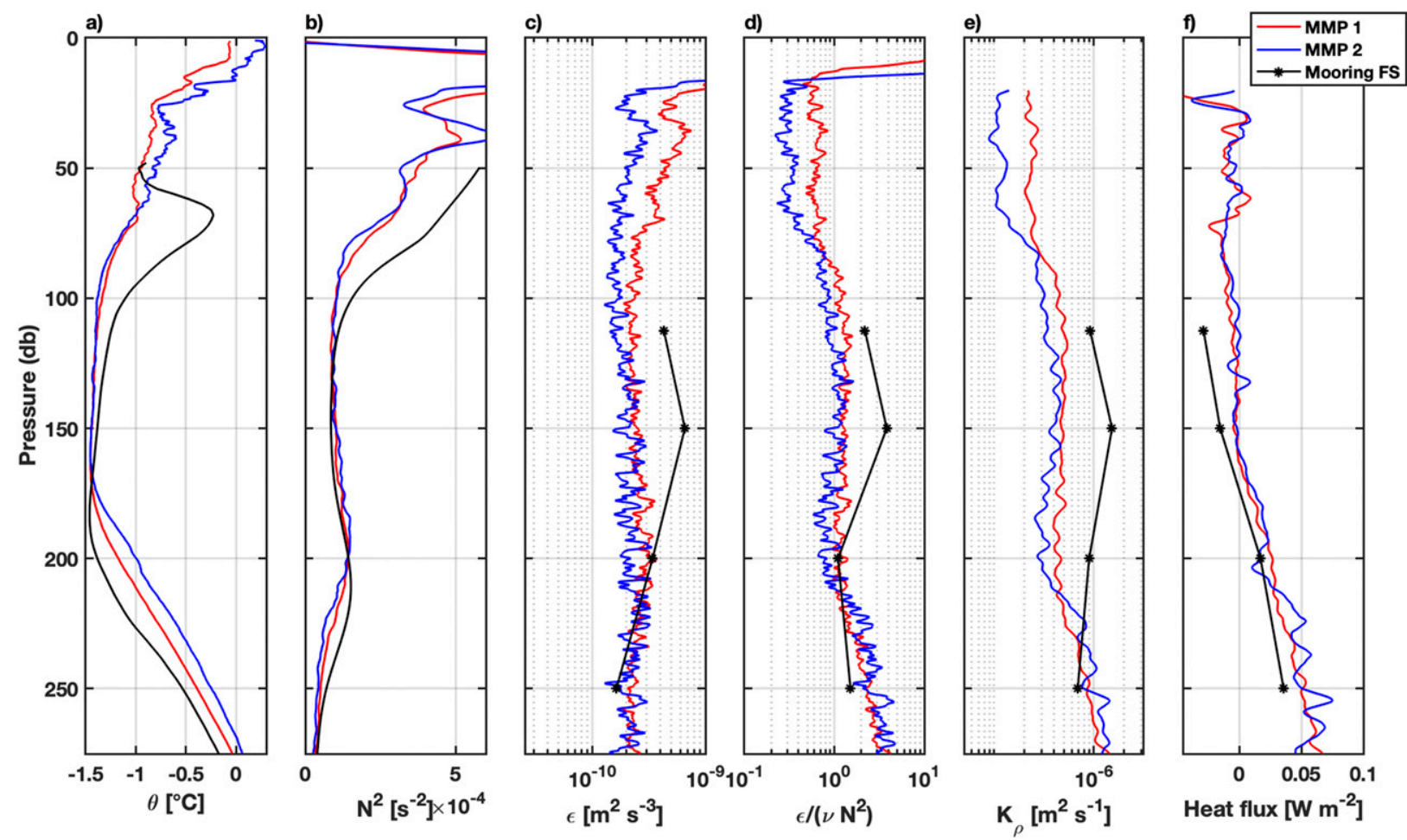

FIG. 2. Quantities averaged over MMP surveys one (red) and two (blue), and averaged over the moored profiler record (black): (a) potential temperature, (b) $N^{2}$, (c) $\varepsilon$, (d) $\mathrm{Re}_{b}$, (e) $K_{\rho}$, and (f) heat flux. Black stars represent finescale estimates calculated at the mooring site using shear and strain moored profiler measurements to calculate $R_{\omega}$ in situ. The dotted black line in (c) indicates the instrument's noise floor.

survey, only strain is available due to poor data quality of the shipboard ADCPs, so $R_{\omega}$ is set equal to the time average of $R_{\omega}$ observations at the mooring during the microstructure profiler survey.

From about 200 to $300 \mathrm{~m}$, the thermohaline stratification is unstable to double diffusive convection. However, inspecting individual profiles we do not generally find double diffusive layers in the 2-m binned profiles, with the exception of 30 profiles in which one or more layers were found below $250 \mathrm{~m}$. We excluded these profiles from the finescale analysis in this depth range.

\section{Oceanographic context}

\section{a. Sea ice and hydrography}

The summer of 2015 saw persistent sea ice in the Beaufort Sea, with patches of $10 \%-20 \%$ ice concentrations persisting throughout September. A wind event that will be discussed in the sections that follow occurred on 30 August 2015. At this time, the study region had low (less than $8 \%$ ) sea ice concentrations (Fig. 1).

Stratification in the western Arctic is almost entirely controlled by variations in salinity, due to a combination of large freshwater input and low temperatures which minimize the role temperature plays in setting density (Figs. 2a,b). The mean stratification profile over the duration of the mooring deployment is characterized by relatively high stratification from 50 to
$70 \mathrm{~m}\left(N^{2}=6 \times 10^{-4} \mathrm{rad} \mathrm{s}^{-2}\right)$, which decays rapidly to about $150-\mathrm{m}$ depth. This region is characterized by relatively cool and freshwater, with a local temperature maximum at $\sim 50 \mathrm{~m}$ that is characteristic of Pacific Summer Water and a local minimum at $\sim 100 \mathrm{~m}$ indicating the Pacific Winter Water. A second local maximum in stratification occurs between 150 and $250 \mathrm{~m}$, with $N^{2}$ reaching values of about $2 \times 10^{-4} \mathrm{rad}^{2} \mathrm{~s}^{-2}$. This secondary peak is associated with the top of the Atlantic Water. Beneath $250 \mathrm{~m}$, the stratification rapidly decays, with $N^{2}$ reaching a value of $1.8 \times 10^{-6} \mathrm{rad}^{2} \mathrm{~s}^{-2}$ at $750 \mathrm{~m}$.

\section{b. Mooring observations}

Near-inertial frequencies dominate both the velocity and isopycnal displacement signals, with upward-tilting contours of velocity in a depth-time plot indicating these are surfacegenerated, downward-propagating near-inertial internal waves (NIWs, Fig. 3 Gill 1982). The NIWs appear following peak wind speeds of $12 \mathrm{~m} \mathrm{~s}^{-1}$ two days before the deployment (Fig. 3a).

At the latitude of our observations, the inertial frequency $\left(f=1.387 \times 10^{-4} \mathrm{rad} \mathrm{s}^{-1}\right)$ is quite close to the M2 tidal frequency $\left(1.406 \times 10^{-4} \mathrm{rad} \mathrm{s}^{-1}\right)$, so that we are unable to distinguish these two frequency bands over the mooring record. Tides are quite weak in the western Arctic, with maximum modeled barotropic tidal velocities of approximately $0.2 \mathrm{~cm} \mathrm{~s}^{-1}$ at the mooring site. The appearance of nearinertial waves does not coincide with the barotropic spring 

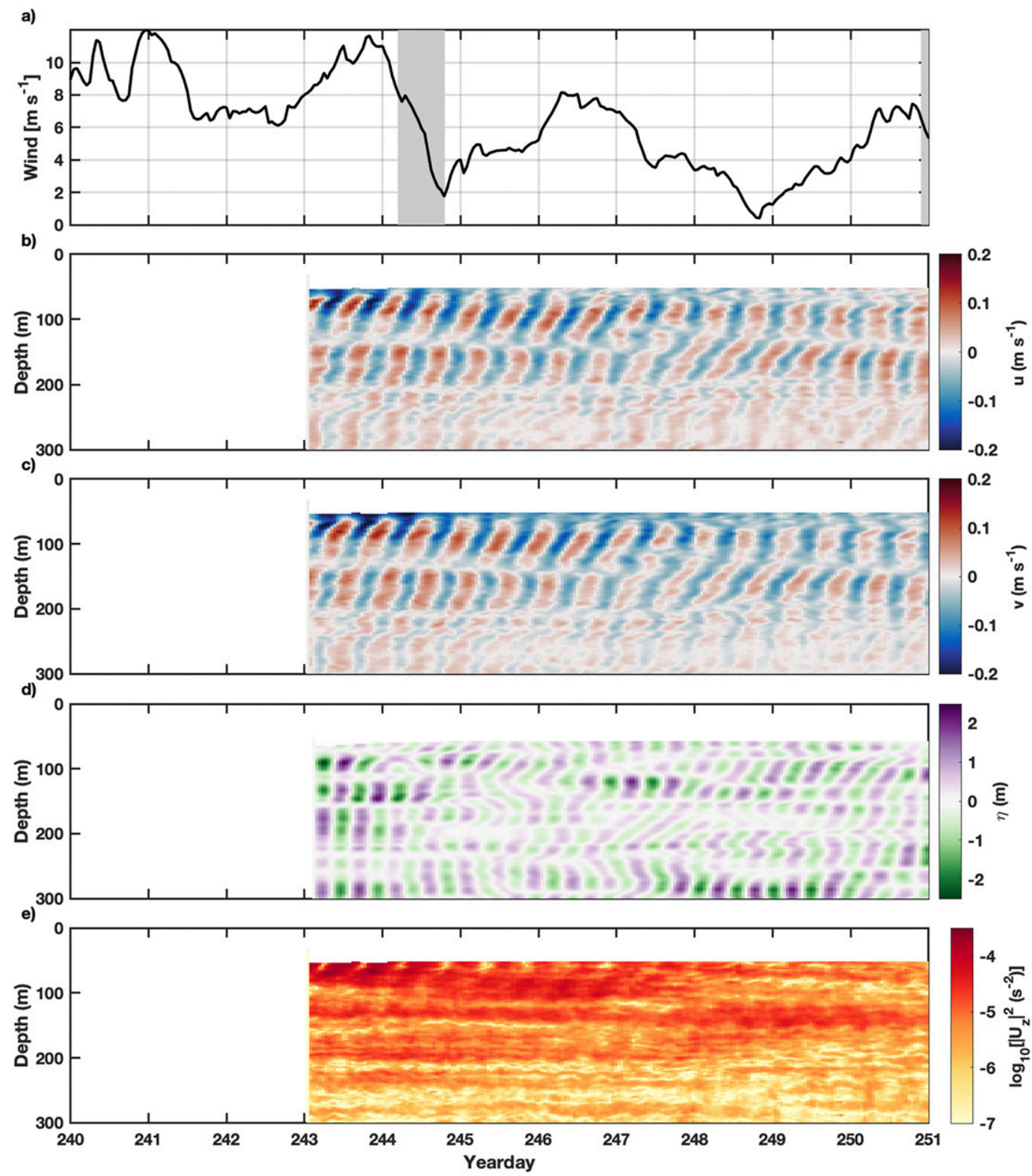

FIG. 3. (a) The 10-m wind speed from the CFSv2 reanalysis product with the timing of the two MMP surveys shaded in gray, (b) $u$ velocity $\left(\mathrm{m} \mathrm{s}^{-1}\right)$, (c) $v$ velocity $\left(\mathrm{m} \mathrm{s}^{-1}\right)$, (d) isopycnal displacement $\eta(\mathrm{m}),(\mathrm{e}) \log _{10}\left[\left|\mathbf{U}_{z 20 \mathrm{~m}}\right|^{2}\left(\mathrm{~s}^{-2}\right)\right]$. All observations are from the moored profiler.

tide, and internal tides tend to be low mode unlike the observed features, leading us to conclude that the observed near-inertial signal is generated by wind forcing rather than the internal tide.

Horizontal kinetic energy density $\left[\mathrm{HKE}=1 / 2\left(u^{2}+v^{2}\right)\right]$, in which $u$ and $v$ are the zonal and meridional velocity components) is also dominated by downward energy propagation from the surface to about $200 \mathrm{~m}$ (Fig. 4). A second pulse of energy centered around $175-\mathrm{m}$ depth is apparent. Shear $\left(\mathbf{U}_{z 20}^{2}=u_{z 20}^{2}+v_{z 20}^{2}\right)$ is elevated at $50 \mathrm{~m}$, and decays with depth around $200 \mathrm{~m}$ (Fig. 3e). The Richardson number $\left(\mathrm{Ri}_{20}^{-1} \equiv \mathbf{U}_{z 20}^{2} / N_{20}^{2}\right)$, in which $\mathbf{U}_{z 20}$ is the vertical shear of horizontal currents and $N_{20}$ is the local buoyancy frequency, does not indicate the presence of shear instabilities at scales of $20 \mathrm{~m}$ or larger.

\section{Results}

\section{a. Microstructure observations}

During both microstructure surveys, we find that $\varepsilon$ is generally quite low $\left(\varepsilon<3 \times 10^{-10} \mathrm{~W} \mathrm{~kg}^{-1}\right)$ beneath $50 \mathrm{~m}$ (Fig. 2c). Both $\varepsilon$ and the buoyancy Reynolds number $\left(\operatorname{Re}_{\nu}=\varepsilon / \nu N^{2}\right)$ are elevated by a factor of 2-3 between 25 and 


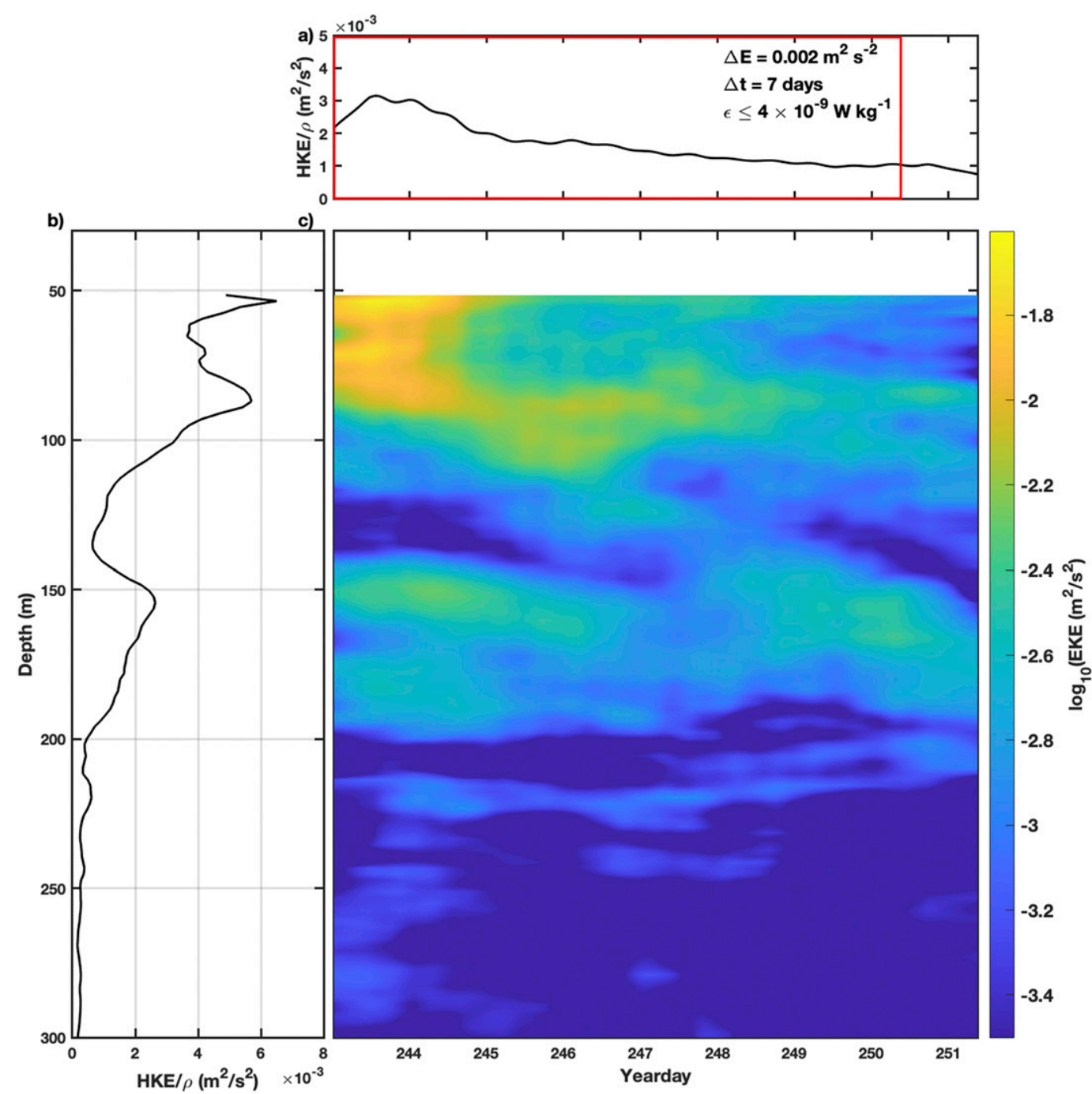

FIG. 4. Horizontal kinetic energy density calculated from the moored profiler velocities (a) depth-averaged from 50 to $300 \mathrm{~m}$, (b) time-averaged over the profiler record, and (c) over the course of the mooring record (smoothed over $24 \mathrm{~h}$ ). The period used to determine an upper bound on $\varepsilon$ due to the dissipation of the NIW is highlighted in red in (a).

$125 \mathrm{~m}$ in the survey that took place on yearday 244 during the NIW event, relative to the survey undertaken on yearday 251 (Figs. 2c,d). This elevation suggests the NIW event was associated with measurably increased $\varepsilon$ in the upper water column, even at the low $\varepsilon$ levels observed throughout both surveys. The maximum value of $\varepsilon=6 \times$ $10^{-10} \mathrm{~W} \mathrm{~kg}^{-1}$ was found at 30-m depth during the survey on yearday 244 (excluding depths less than $20 \mathrm{~m}$ due to potential ship wake contamination). Deeper than $150 \mathrm{~m}, \varepsilon$ was not elevated during the first survey.

Calculated diapycnal diffusivities and heat fluxes from MMP surveys 1 and 2 and from $\varepsilon_{\mathrm{fs}}$ are quite low, with estimated thermal diffusivities 5-10 times molecular thermal diffusivity and all estimated heat flux magnitudes less than $0.06 \mathrm{~W} \mathrm{~m}^{-2}$ (Figs. 2,e,f). As $\operatorname{Re}_{\nu}$ is also quite low (Fig. 2d), these results should be treated as upper bounds as turbulence is likely anisotropic. Low $\operatorname{Re}_{\nu}$ may also affect mixing efficiency directly (Gregg et al. 2018).

\section{b. Finescale parameterizations}

Mean shear and strain wavenumber and frequency spectra in each of the finescale depth bins over the moored profiler deployment were approximately an order of magnitude less energetic than GM76 levels (Figs. 5a-d and 5e-h, Table 1), consistent with a number of internal wave observations in the western Arctic (e.g., Morison et al. 1985; Levine et al. 1985; Pinkel 2005). Rotary frequency spectra showed broad peaks around the inertial and tidal frequencies in the negative (anticyclonic) portion of the spectra, consistent with downward propagating near-inertial waves.

Below we present in situ measurements of the ratio of normalized shear to strain variance $R_{\omega}$, followed by estimates $\varepsilon_{\mathrm{fs}}$ as 
a) $75-150 \mathrm{~m}$

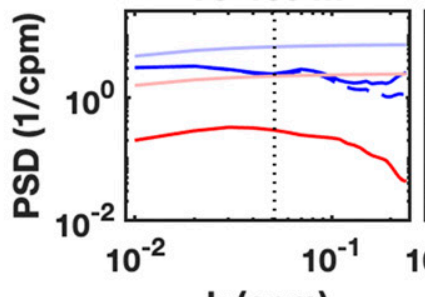

e) $\mathrm{k}(\mathrm{cpm})$

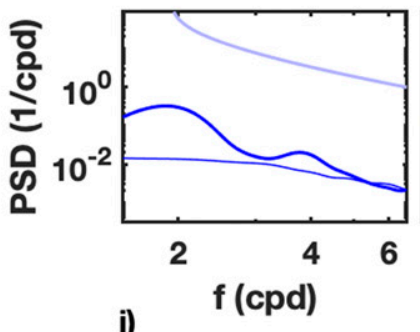

b) $100-200 \mathrm{~m}$

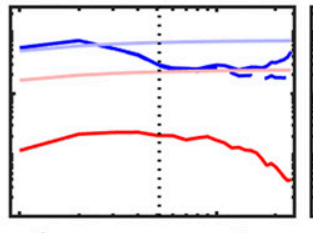

c) $150-250 \mathrm{~m}$

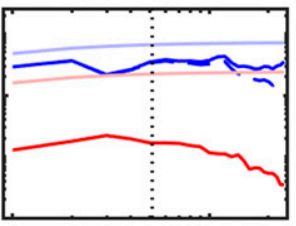

$10^{-2} \quad 10^{-1} \quad 10^{-2}$ d) $200-300 \mathrm{~m}$

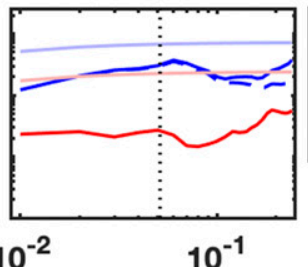

h) $k$ (cpm)

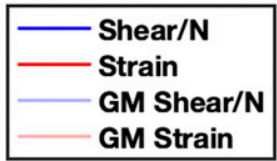

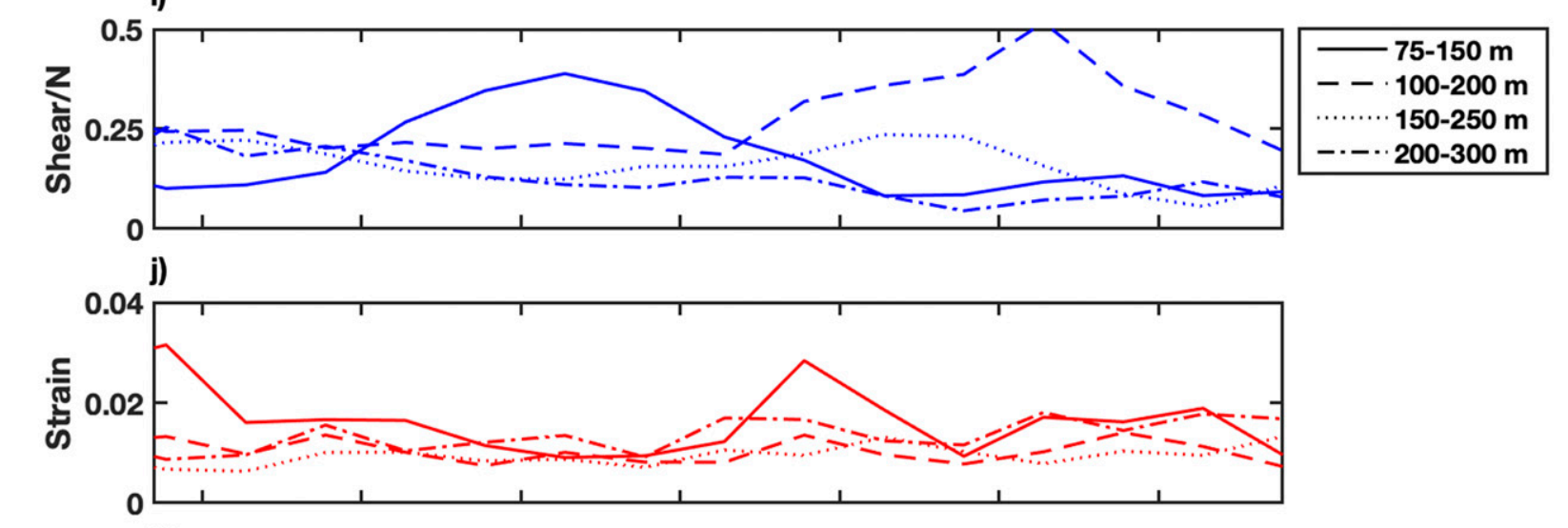

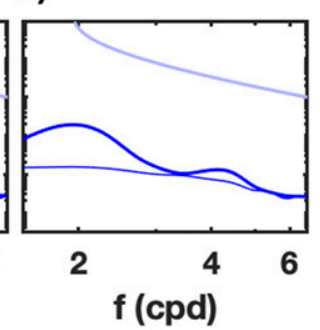

g)
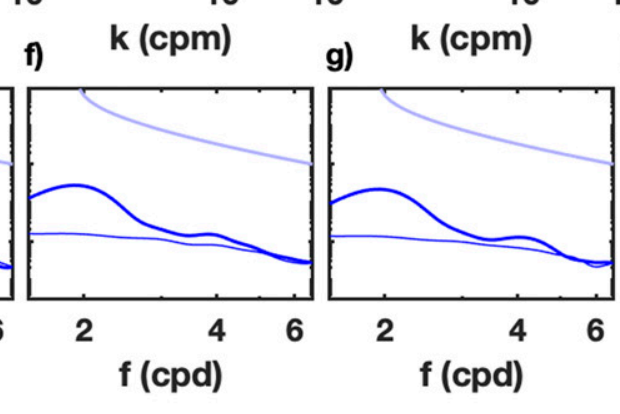

$\mathrm{k}(\mathrm{cpm})$
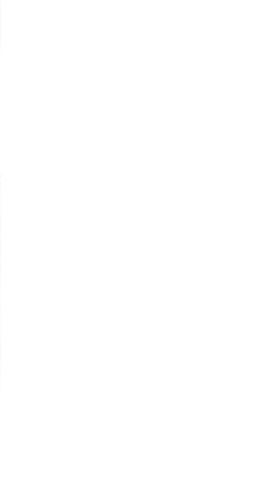

k)
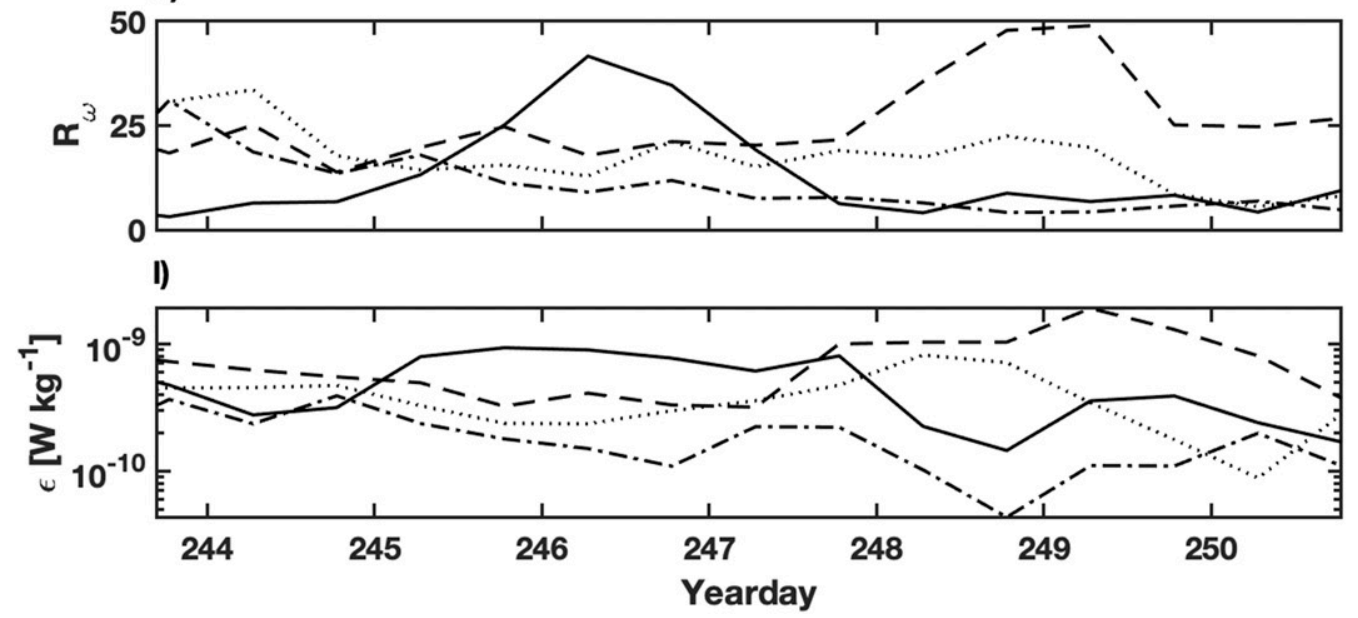

FIG. 5. Average normalized shear (blue) and strain (red) wavenumber spectra for depth bins (a) 75-150, (b) 100-200, (c) 150-250, and (d) 200-300 m. Light blue and red lines are the GM76 normalized shear and strain wavenumber spectra for each depth bin. Normalized shear spectra uncorrected for binning are shown as dotted lines. The wavenumber cutoff $k_{c}=0.04 \mathrm{~m}^{-1}$ used for integration is shown as a dotted black line. Average normalized shear frequency spectra for bins (e) 75-150, (f) 100-200, (g) 150-250, and (h) 200-300 m. Heavy and light lines represent negative and positive frequencies, respectively. Light blue lines are the GM76 shear frequency spectra for each depth bin. Time series plots for 12-h finescale estimates of (i) normalized shear, (j) strain, (k) in situ $R_{\omega}$, and 1$) \log _{10}\left(\varepsilon_{\mathrm{fs}}\right)$ for all depth bins. Line style indicates depth bins, with the 75-150-m depth bin solid, 100-200 m dashed, 150-250 m dotted, and 200-300 m dash-dot. 
calculated for both the first microstructure survey and the moored profiler deployment. For the microstructure survey, a strain-based parameterization is used, with the in situ values of $R_{\omega}$ applied to strain data from the microstructure profiler's CTD package. At the mooring location, the finescale parameterization is applied to the moored profiler data using local strain and shear.

\section{1) RATIO OF SHEAR TO STRAIN}

The ratio of normalized shear to strain variance features prominently in the finescale parameterization as the nondimensional number $R_{\omega}=\left\langle U_{z}^{2}\right\rangle /\left(\overline{N^{2}}\left\langle\zeta_{z}^{2}\right\rangle\right)$. Many studies assume a set value of either 3 or 7 for $R_{\omega}$. However, the concurrent shear and strain measurements from the moored profiler permits the calculation of $R_{\omega}$ directly from observations (Figs. 5e-g). The ratio $R_{\omega}$ varies substantially in both time and in depth, with a mean value of 17 (95\% confidence interval 14-20), a standard deviation of 11, and a range from 3 to 50. Elevated values of $R_{\omega}$ occur due to the strong near-inertial component of the internal wavefield, leading to the dominance of kinetic over potential energy.

\section{2) RATE OF TURBULENT DISSIPATION ESTIMATES}

\section{(i) Microstructure survey}

For a direct comparison with microstructure observations, we calculate a strain-based finescale parameterization using hydrographic data collected by the microstructure profiler during the first microstructure survey. Time-mean values of $R_{\omega}$ for each depth window are calculated from the mooring strain and shear data time-averaged over the first microstructure survey (Fig. 6b). The mean $\varepsilon_{\mathrm{fs}}$ estimates calculated from the MMP survey are within a factor of 1.5 of the observed microstructure measurements in the 75-150-, 150-250-, and 200300-m-depth windows; however, in the 100-200-m-depth window the finescale estimates are approximately a factor of 4 larger than microstructure observations. The strain-based parameterization results from the microstructure survey data are within a factor of 2 of a strain- and shear-based parameterization at the mooring location averaged over the duration of the microstructure survey.

\section{(ii) Mooring}

Estimates of $\varepsilon_{\mathrm{fs}}$ from a strain- and shear-based parameterization applied at the mooring site are uniformly low (less than $10^{-9} \mathrm{~W} \mathrm{~kg}^{-1}$ ), consistent with historic observations (Fig. 5h). Generally, $\varepsilon_{\mathrm{fs}}$ varies with shear, which is mostly dominated by the near-inertial signal, more strongly than with strain. Estimates vary over approximately an order of magnitude over the 8-day record.

\section{Discussion}

\section{a. Finescale parameterizations}

Finescale parameterizations that were developed empirically based on observations at midlatitudes could lead to erroneous results in the western Arctic for a number of reasons. These reasons include concentration of energy in a strong near-inertial peak in the frequency distribution (Figs. 5e-h), an order of magnitude lower energy observed in the internal wavefield compared to the Garrett-Munk spectra, which could result in an underestimate of $\varepsilon$ (Figs. 5a-d; Winters and D'Asaro 1997), and the latitude correction used in this study which has only been tested at low latitudes (Gregg et al. 2003). In spite of many possible sources of error, existing studies suggest that finescale parameterizations applied in the western Arctic produce estimates that are consistent with both historic and modern observations (Guthrie et al. 2013, 2015; Lique et al. 2014; Chanona et al. 2018; Chanona 2020). Here we discuss the applicability of the finescale parameterization in the current study, focusing on the effect of varying $R_{\omega}$ and the observed discrepancies between the parameterization and microstructure measurements.

\section{1) VARIABILITY OF $R_{\omega}$ OVER THE MOORING DEPLOYMENT}

In one of the few studies explicitly considering temporal variance of $R_{\omega}$, Chinn et al. (2016) analyzed shear and strain from five moored profiler experiments and found that $R_{\omega}$ varied substantially in the presence of near-inertial waves, although the observed range for $R_{\omega}$ was smaller than found in the current study. This is consistent with our observations, in which the largest values of $R_{\omega}$, found from 75- to 100-m-depth yeardays 245-247 and from 100- to 200-m-depth yeardays 248-249, were associated with maximal values of shear (Figs. 5i,k). The total kinetic energy density (Fig. 4c) was highest at these depths during the same period that shear and $R_{\omega}$ were highest, suggesting that the largest values of $R_{\omega}$ were associated with the propagation of the NIW packet. Conversely, $R_{\omega}$ was uniformly low from 200 to $300 \mathrm{~m}$, where kinetic energy density was also low throughout the mooring deployment.

Recall that the dependence of the $h_{1}$ and $h_{2}$ functions on $R_{\omega}$ determine how changes in $R_{\omega}$ affect the shear- or strain-based parameterizations. The error introduced by underestimating $R_{\omega}$ increases as a function of true $R_{\omega}$. For example, $R_{\omega}=10$ implies $h_{2}=4$, while $R_{\omega}=50$ implies $h_{2}=40$. Applying strainbased finescale parameterizations assuming a Garrett-Munk value of $R_{\omega}=3$ and $h_{2}=1$ (as is sometimes done in the absence of velocity data) can therefore deviate more than an order of magnitude from parameterizations using local strain and shear when the internal wavefield is dominated by near-inertial shear. In the current study, estimating $\varepsilon_{\mathrm{fs}}$ using a timeaveraged vertical profile for $R_{\omega}$ calculated over the entire mooring record rather than allowing for $R_{\omega}$ to vary in time does not affect results substantially, although in this time-averaged profile $R_{\omega}$ does vary significantly with depth. Using a constant $R_{\omega}=3$ (consistent with a Garrett-Munk spectrum) results in discrepancies of up to an order of magnitude compared with using in situ $R_{\omega}$ (Fig. 6a). At all depths, mean $R_{\omega}$ is greater than three, so that the shear-based (strain-based) parameterization assuming $R_{\omega}=3$ overestimates (underestimates) $\varepsilon$ relative to the results obtained with in situ $R_{\omega}$. The discrepancy is larger for strain than for shear, consistent with the variation of $h_{1}$ and $h_{2}$ when $R_{\omega}$ is greater than three.

Ideally, accurate estimates of $R_{\omega}$ could be inferred from local measurements of only shear or strain. Following 

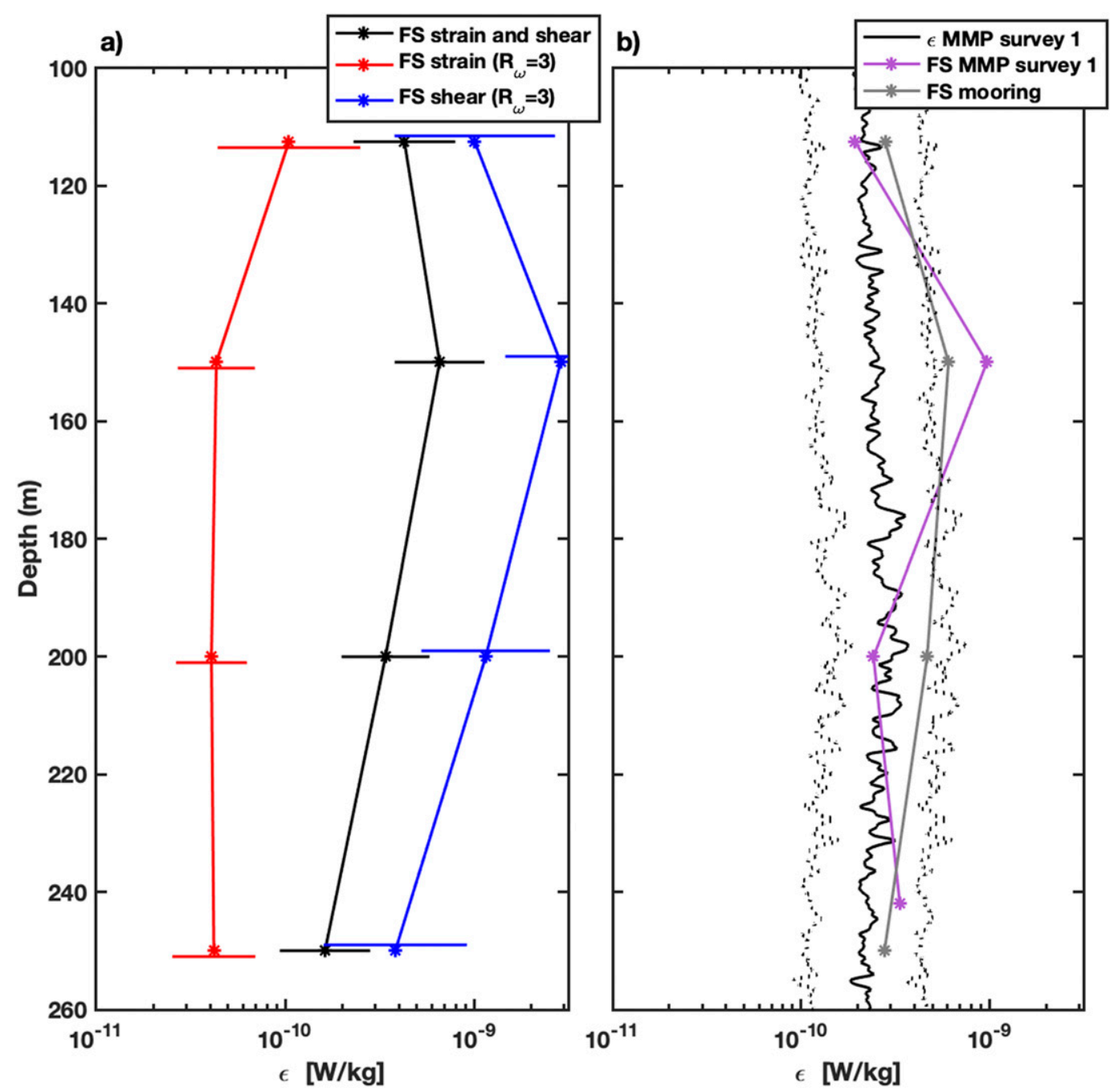

FIG. 6. (a) $\varepsilon_{\mathrm{fs}}$ averaged over the entire mooring duration. The black stars show finescale estimates made using both strain and shear spectra (both the strain and shear formulations give the same answer using locally calculated $R_{\omega}$ ). The red and blue stars show estimates made using only shear and only strain spectra, using the ratio $R_{\omega}=3$ in both cases. Standard deviations of each estimate over the mooring record are shown as colored bars. (b) $\varepsilon$ during MMP survey 1 inferred from direct microstructure measurement in black, with dotted lines showing factor of 2 bounds around this estimate. Purple stars show finescale estimates made from strain spectra calculated using the CTD data obtained by the microstructure profiler, using depth-varying $R_{\omega}$ as calculated from the mooring shear and strain records during the MMP survey 1. Gray stars show the finescale estimate using both shear and strain from the mooring data during MMP survey 1.

Chinn et al. (2016), we calculate least squares fits relating $R_{\omega}$ to $\left\langle U_{z}\right\rangle /\left\langle U_{z}^{\mathrm{GM}}\right\rangle\left(R_{\omega}=30 \times\left\langle U_{z}\right\rangle /\left\langle U_{z}^{\mathrm{GM}}\right\rangle-1.5\right.$; with $\left.R^{2}=0.78\right)$ and to $\left\langle\zeta_{z}\right\rangle /\left\langle\zeta_{z}^{\mathrm{GM}}\right\rangle\left(R_{\omega}=-120 \times\left\langle\zeta_{z}\right\rangle /\left\langle\zeta_{z}^{\mathrm{GM}}\right\rangle+31\right.$; with $R^{2}=$ 0.32 ; Fig. 7). Shear is a better predictor of $R_{\omega}$ than strain, due to the dominance of near-inertial motions. The slope and intercept of the shear fit is within the range observed by Chinn et al. (2016), while both the slope and intercept of strain are well outside the corresponding range. This discrepancy may be partially explained by the much lower strain energies compared to these other observations; the mean strain energy observed in this study is an order of magnitude smaller than the GM value, in contrast to the observations discussed by Chinn et al. (2016), which are all greater than GM.

\section{2) DiSCREPANCIES IN THE FINESCALE PARAMETERIZATION}

The comparison between microstructure inferred $\varepsilon$ and the strain-based parameterization applied to CTD data collected during the microstructure survey found $\varepsilon_{\mathrm{fs}}$ biased high relative to $\varepsilon$ between 100 and $200 \mathrm{~m}$ by approximately a factor of 4 (Fig. 6b). A number of possible explanations could account for this discrepancy. First, both the CTD observations and the mooring strain and shear observations used to calculate $R_{\omega}$ 


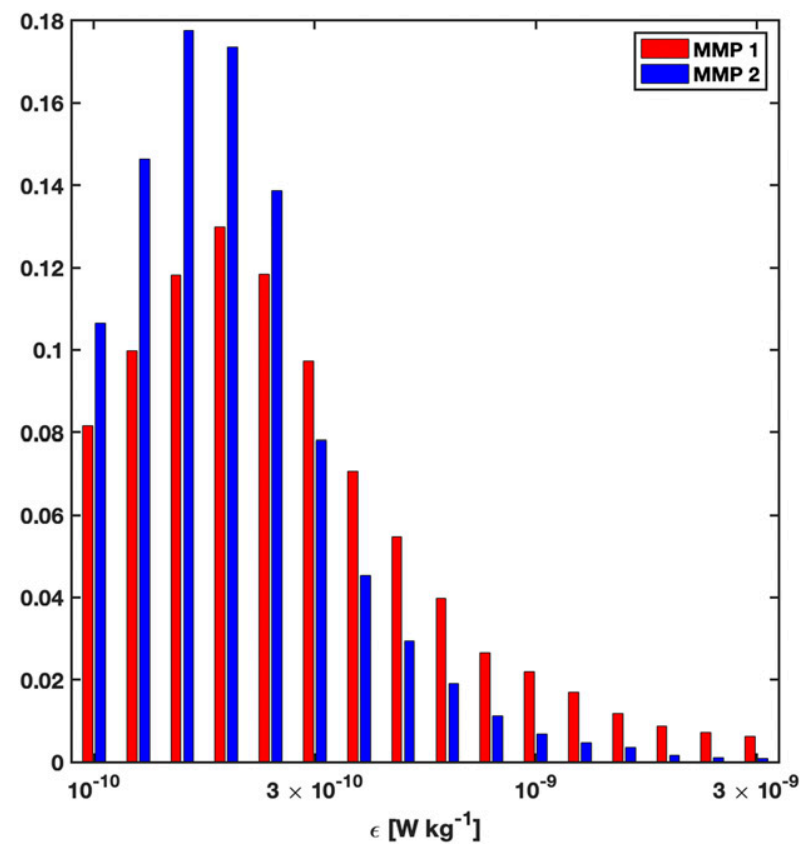

FIG. 7. Histograms of $\varepsilon$ measured during MMP surveys 1 (red) and 2 (blue). The instrument noise floor is $1 \times 10^{-10} \mathrm{~W} \mathrm{~kg}^{-1}$, and values are capped there. In both surveys there are peaks in the distribution between 1 and $3 \times 10^{-10} \mathrm{~W} \mathrm{~kg}^{-1}$, suggesting that observed patterns are physically meaningful, if subject to overestimation.

occurred during a near-inertial wave event. The finescale parameterization depends on the assumption that the internal wave field is in a stationary state, and this assumption may have been violated due to the injection of energy in the nearinertial band, which would bias $\varepsilon_{\mathrm{fs}}$ high at both sites. This explanation is consistent with the smaller discrepancies observed in the top and bottom bins, in which shear spectra were less energetic. In this case, $\varepsilon_{\mathrm{fs}}$ estimates at the mooring location would also be biased high relative to true $\varepsilon$. It is possible that the finescale parameterization is generally less accurate when the internal wavefield is dominated by nearinertial frequencies, as these slower waves are more susceptible to interaction with mesoscale currents or direct breaking (Waterman et al. 2014; Alford and Gregg 2001).

Another potential reason for the discrepancy is the different forcing at the mooring location and microstructure survey site, which could invalidate the assumption that $R_{\omega}$ observed at the mooring site can be applied to the microstructure survey. While we have assumed internal wave dynamics are similar at the mooring location and the microstructure site, the results of a slab model calculation indicate nearly a factor of 2 greater mean energy flux from the wind to the ocean between yeardays 240 and 242 at the mooring than at the microstructure survey site $\left(1.0 \times 10^{-2} \mathrm{~W} \mathrm{~m}^{-2}\right.$ compared to $6 \times 10^{-3} \mathrm{~W} \mathrm{~m}^{-2}$; see appendix). Thus, excess near-inertial shear at the mooring location could result in higher $R_{\omega}$ at the mooring than at the microstructure survey site. Strain spectra during the microstructure survey are quite similar to those observed at the mooring during the microstructure survey; however, NIWs a)
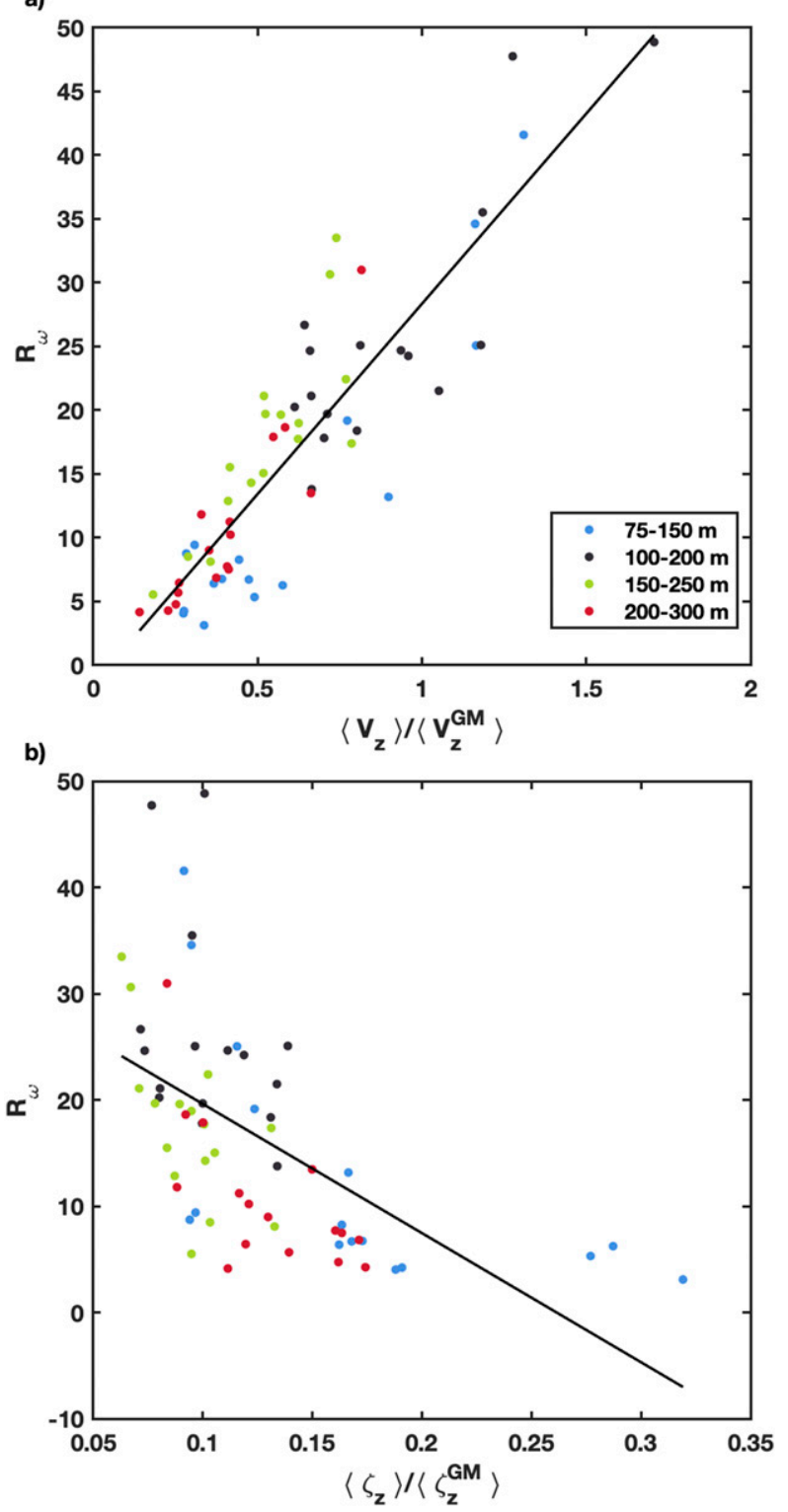

FIG. 8. Scatterplots of $R_{\omega}$ as a function of (a) $\left\langle U_{z}\right\rangle /\left\langle U_{z}^{\mathrm{GM}}\right\rangle$ and (b) $\left\langle\zeta_{z}\right\rangle /\left\langle\zeta_{z}^{\mathrm{GM}}\right\rangle$, with least squares linear regression fits in black. Points are colored by depth window.

have very little potential energy so the strain signal is less sensitive to their presence. This explanation would also result in a high bias for $\varepsilon_{\mathrm{fs}}$ at the microstructure survey location. In this case, true $\varepsilon$ at the mooring would be higher than that observed at the microstructure survey site.

Finally, the finescale parameterization as formulated for use at lower latitudes may have a more general bias in the Arctic, due to the many differences between this environment and the mid- to low latitudes. While this possibility cannot be fully discounted, the good agreement between $\varepsilon$ and $\varepsilon_{\mathrm{fs}}$ in all other windows (in which shear spectra were less energetic during the microstructure survey) suggests that the discrepancies 
observed between 100 and $200 \mathrm{~m}$ are likely due to the nearinertial wave event and not indicative of a more general bias.

Recall that the finescale parameterization was also applied to the mooring using strain and shear measured by the moored profiler (Fig. 2c). Comparing this $\varepsilon_{\mathrm{fs}}$ estimate averaged over the entire mooring deployment with $\varepsilon$ as measured in both microstructure surveys, the microstructure estimates of $\varepsilon$ are generally in agreement with $\varepsilon_{\mathrm{fs}}$ to within a factor of 2 , except for in the 100-200-m finescale depth window, in which they agree within a factor of 3 . The improved agreement between microstructure and finescale estimates when the entire mooring record is considered is consistent with the nonstationarity of the internal wavefield during the period that corresponded to the microstructure survey contributing to an overestimation of $\varepsilon$.

One potential concern in these comparisons is that the observed values of $\varepsilon$ are close to the $10^{-10} \mathrm{~W} \mathrm{~kg}^{-1}$ noise floor of the MMP (Gregg 1999). Histograms over both surveys show peaks at the instrument noise floor, implying that the true value of $\varepsilon$ does often fall below $10^{-10} \mathrm{~W} \mathrm{~kg}^{-1}$. However, both survey distributions have primary peaks around $2 \times 10^{-10} \mathrm{~m}^{2} \mathrm{~s}^{-3}$, with a slightly higher mean in the earlier survey (Fig. 7). This suggests that averages calculated from the data are physically meaningful, though potentially subject to overestimation. The buoyancy Reynolds numbers calculated during each survey suggest that even during the more energetic survey, dissipation rates were not strong enough to result in fully developed isotropic turbulence, as indicated by values of $\operatorname{Re}_{\nu}$ less than $25\left(\log _{10} 25=1.39\right)$. Anisotropic turbulence may result in overestimation of $\varepsilon$, as variance in the vertical tends to be higher than in the horizontal due to the tendency of shear to spread eddies laterally (Smyth and Moum 2000).

\section{b. NIW energy loss}

So far we have considered the role of energetic NIWs in ocean mixing insofar as their presence modulates $R_{\omega}$ within a range of 3-50. However, these NIWs also provide a direct pathway for the vertical transfer of energy from the ocean's surface, potentially carrying energy to the depth of the Atlantic Water. Here we compare the rate of observed NIW energy loss to the estimates of $\varepsilon$ from microstructure and finescale analysis.

Using a slab model (Pollard and Millard 1970) and the NCEP CFSv2 hourly time series, we estimate the power input from the wind into the ocean's mixed layer (appendix). The slab model confirms that the wind event likely caused inertial oscillations at the microstructure survey sites as well as at the mooring, although there was less energy input at the microstructure survey sites. While sea ice was present at this time, we assume [consistent with modeling work done by Martin et al. (2014)] that the ice density (less than $8 \%$ ) was too low to have a significant effect on the transfer of wind energy into the upper ocean.

As NIWs travel, their energy dissipates due to instabilities and wave-wave interactions. For a given wave frequency with no local energy sources or sinks aside from dissipation (which we assume to be the case below depths of direct wind-energy input), this is described by the wave energy equation:

$$
\frac{\partial E}{\partial t}+(\mathbf{u} \cdot \nabla) E=\nabla \cdot \mathbf{c}_{g} E-\varepsilon
$$

in which $E$ represents energy, u background velocity (larger length and slower time scales than the internal wave), and $\mathbf{c}_{g}$ the wave group velocity (including both horizontal and vertical components). Between yeardays 243 and 250, the depthaveraged energy density from 50 to $300 \mathrm{~m}$ decreased from approximately $3 \times 10^{-3}$ to $1 \times 10^{-3} \mathrm{~m}^{2} \mathrm{~s}^{-2}$ (Fig. 4a). With $\Delta E=-0.002 \mathrm{~m}^{2} \mathrm{~s}^{-2}$ and $\Delta t=7$ days $=6.048 \times 10^{5} \mathrm{~s}$, we find $\Delta E / \Delta t=-7 \times 10^{-9} \mathrm{~W} \mathrm{~kg}^{-1}$. If this energy were entirely dissipated locally, it would represent a significant source of mixing in the upper ocean. However, observed $\varepsilon$ was an order of magnitude less than this value, while finescale parameterization estimates at the mooring were a factor of 5 smaller. The much larger value of mean $\Delta E / \Delta t$ suggests that lateral advection and/or propagation of internal waves were primarily responsible for the decrease in observed NIW energy, rather than local dissipation.

In the microstructure survey during the NIW event, $\varepsilon$ was elevated by a factor of $2-3$ between 25 and $120 \mathrm{~m}$ relative to the survey after the NIW event. Direct influence on $\varepsilon$ by NIWs has been observed before in the Amundsen Basin, where Fer (2014) observed $\varepsilon$ elevated by up to a factor of 5 between 70 and $150 \mathrm{~m}$ during strong near-inertial motions. In contrast, in the Canada Basin following a storm Lincoln et al. (2016) did not observe increased $\varepsilon$ associated with near-inertial waves at any depth, except in the presence of sloping topography.

Both microstructure surveys found small and nearly identical dissipation rates at the depth of the Atlantic Water. This result is consistent with studies by Lincoln et al. (2016), Guthrie et al. (2013), and Lique et al. (2014), all of which found that a decline in sea ice cover has not been associated with elevated mixing at the intermediate depths where Atlantic Water is found in the western Arctic ocean. While the microstructure survey was physically separated from the mooring site, the finescale parameterization at the mooring also did not show evidence of increased shear or $\varepsilon_{\mathrm{fs}}$ at Atlantic Water depths.

The low dissipation rates found in this study imply a slow rate of downscale energy transfer within the inertial subrange of the internal wavefield. The central equation of the finescale parameterization can be written as

$$
\begin{aligned}
\mathscr{P}= & 8 \times 10^{-10} \frac{f}{f_{30}} \frac{N^{2} \cosh ^{-1}(N / f)}{N_{0}^{2} \cosh ^{-1}\left(N_{0} / f_{30}\right)} \widehat{E^{2}} \frac{3\left(R_{\omega}+1\right)}{4 R_{\omega}} \\
& \times \sqrt{\frac{2}{R_{\omega}-1}}\left(\mathrm{~W} \mathrm{~kg}^{-1}\right) .
\end{aligned}
$$

This form can be derived from the energy density equation for an internal wavefield by equating turbulent productivity $\mathscr{P}$ to the rate of downscale energy transfer due to wave-wave interactions within an inertial subrange and applying a number of simplifying assumptions (Polzin et al. 2014). Provided that these assumptions hold well enough for back-of-the-envelope calculations in this environment (which is supported by the good agreement observed between the finescale parameterization and microstructure observations) we can assess the 
effect that latitude, stratification, energy level, and frequency distribution (as represented by $R_{\omega}$ ) have on the rate of downscale energy transfer. Latitude and stratification influence downscale energy transfer by the factor

$$
\frac{f}{f_{30}} \frac{N^{2} \cosh ^{-1}(N / f)}{N_{0}^{2} \cosh ^{-1}\left(N_{0} / f_{30}\right)} .
$$

In a GM environment, this factor reduces to 1 ; in the current setting it is about a factor of 7 . The total energy $\widehat{E^{2}}$ in the present case is about a factor of 3 less than $E_{\mathrm{GM}}^{\hat{2}}$. The effect of $R_{\omega}$ is represented by

$$
\frac{3\left(R_{\omega}+1\right)}{4 R_{\omega}} \sqrt{\frac{2}{R_{\omega}-1}} ;
$$

using the mean value $R_{\omega}=17$, we find that this factor is smaller than the GM by about a factor of 4 . Thus, the combined influence of high $f$ and $N$, which tend to increase the rate of dissipation and downscale energy transfer, partially balances the tendency of low energy and high $R_{\omega}$ (due to the dominance of near-inertial shear) to decrease these rates. Overall, the mean dissipation rate found in this study is a factor of 2-3 smaller than GM dissipation, implying that downscale energy transfer also proceeds at a rate 2-3 times slower than in the GM case. A distinct but related question is how quickly the inertial subrange adjusts when narrowband frequency forcing (in this case, at the inertial frequency) is applied. To our knowledge this has not been investigated in the Arctic and is beyond the scope of the current study; however, recent work by Le Boyer and Alford (2020, manuscript submitted to J. Phys. Oceanogr.) indicates that there is relatively high temporal variability of energy levels within the internal wavefield (within a factor of 3-10) at various mooring sites in the global ocean. In the current study, the low rates of downscale energy transfer combined with the influence of wind forcing may contribute to the high variability of $R_{\omega}$.

\section{c. Implications for mixing and heat fluxes}

Microstructure observations suggest dissipation rates of $\sim 3 \times 10^{-10} \mathrm{~W} \mathrm{~kg}^{-1}$ between 75 and $150 \mathrm{~m}$ during the first microstructure survey, with a local maximum at $30 \mathrm{~m}$ of $\sim 6 \times$ $10^{-10} \mathrm{~W} \mathrm{~kg}^{-1}$. The finescale parameterization applied at the mooring also resulted in dissipation rates of $3 \times 10^{-10}$ between 75 and $150 \mathrm{~m}$. These dissipation rates correspond to vertical turbulent diffusivities between 75 and $150 \mathrm{~m}$ of $K_{\rho}=4 \times$ $10^{-7} \mathrm{~m}^{2} \mathrm{~s}^{-1}$ during the first microstructure survey and $K_{\rho}=9 \times$ $10^{-7} \mathrm{~m}^{2} \mathrm{~s}^{-1}$ from the mooring finescale parameterization (only 2 times larger than the molecular diffusivity of heat). These values are lower than those found by Guthrie et al. (2013) at both the Yermak Plateau and North Pole sites in 2007 and 2008 and those estimated using a finescale parameterization by Lique et al. (2014) at the Beaufort Gyre Observing System moorings from 2003 to 2011. They are also slightly lower than those reported by Lincoln et al. (2016) in the Canada Basin. Both Guthrie et al. (2013) and Lincoln et al. (2016) report higher instrument noise levels around $5 \times 10^{-10} \mathrm{~W} \mathrm{~kg}^{-1}$, such that the $3 \times 10^{-10} \mathrm{~W} \mathrm{~kg}^{-1}$ values we observed could not be measured; however, given that their reported values for $\varepsilon$ above $150 \mathrm{~m}$ are above these levels this does not explain the discrepancy.

Even immediately following the wind event and ensuing NIWs, observed heat fluxes out of the Atlantic Water were minimal (less than $0.06 \mathrm{~W} \mathrm{~m}^{-2}$ ). For reference, vertical heat fluxes due to double diffusive convection above the Atlantic Water generally range from 0.05 to $0.3 \mathrm{~W} \mathrm{~m}^{-2}$ (Timmermans et al. 2008).

Diffusivities and heat fluxes were slightly elevated in the upper ocean ( $<100 \mathrm{~m}$ depth) during the microstructure survey following the NIW event relative to the later microstructure survey. However, the average temperature profile was warmer at the top and cooler at the bottom, resulting in downward net heat fluxes rather than upward. Mean thermal gradients above $200 \mathrm{~m}$ in the western Arctic are quite variable due to the intermittent presence of PSW, and if NIW forcing generally causes an increase in dissipation above $100 \mathrm{~m}$ as observed in this study episodic upward heat fluxes above PSW filaments may result.

\section{Concluding remarks}

We report the results of concurrent microstructure surveys and finescale parameterizations in the summer ice-free Beaufort Sea following a wind event. Lower values of $\varepsilon$ and diffusivity were inferred from microstructure measurements than have been reported in other microstructure studies in this region.

Shear and strain from a moored profiler were used to estimate finescale parameterized $\varepsilon$. The ratio of shear to strain $R_{\omega}$ varied temporally and with depth from 3 to 50, largely influenced by the presence of near-inertial shear. This large range poses a challenge for the application of solely strain- or shearbased parameterizations, as inaccurate values of $R_{\omega}$ may lead to order of magnitude errors in estimated $\varepsilon$. The current study captured the upper ocean response immediately after a wind event and may not represent typical conditions; however the frequency distribution of the Arctic internal wavefield tends to have a particularly strong near-inertial peak compared to other latitudes, suggesting that $R_{\omega}$ values typically used in studies at lower latitudes may be less applicable in the Arctic. In the absence of concurrent measurements of strain and shear, using depth-dependent values of $R_{\omega}$ based on other regional measurements (e.g., the Beaufort Gyre Observing System moorings) is likely a better option than using constant values.

A local finescale parameterization at the mooring showed relatively good agreement with relatively nearby microstructure estimates of $\varepsilon$, with discrepancies ranging from a factor of 1 to 2.5 depending on depth. The largest discrepancies coincided with the highest shear and suggest an overestimation of true $\varepsilon$, implying that strong NIWs may have biased the finescale parameterization high in these depth ranges. Importantly, comparison of microstructure measurements and the local finescale parameterizations did not indicate a systemic bias in finescale parameterizations in the western Arctic, although more direct comparisons are needed to build confidence in this result. 
Microstructure measurements suggest $\varepsilon$ at depths of 25$120 \mathrm{~m}$ was 2-3 times higher during the early part of study period compared to the end. This difference could be due to the mixing generated by NIWs. Beneath $150 \mathrm{~m}$ no change in dissipation was observed. Heat fluxes were low throughout the water column, with Atlantic Water heat fluxes lower than predicted from background double diffusion. If NIW forcing generally causes an increase in dissipation above $100 \mathrm{~m}$, upward heat fluxes above PSW may result; however this possibility was not observed in the current study due to the lack of PSW during the microstructure surveys.

Acknowledgments. This work was supported by NSF Grants PLR 14-56705 and PLR-1303791 and by NSF Graduate Research Fellowship Grant DGE-1650112. The hourly NCEP CFSv2 model data are made available by NCAR (https:// rda.ucar.edu/datasets/ds094.1/). Winds from Point Barrow are made available by NOAA ESRL (ftp://aftp.cmdl.noaa.gov/ data/meteorology/in-situ/README). The Arctic Ocean Tidal Inverse Model (AOTIM-5) data are made available by the Earth and Space Research Institute (ESR; https:/www.esr.org/ research/polar-tide-models/list-of-polar-tide-models/aotim-5/). Sea ice data is made available by the National Snow and Ice Data Center (https://nsidc.org/data/NSIDC-0081/versions/1).

We gratefully acknowledge the R/V Sikuliaq captain and crew, the Multiscale Ocean Dynamics engineering team, and ArcticMix collaborators who made this study possible. We are additionally grateful to Mike Gregg, Tom Weingartner, John Guthrie, Jim Thomson, Justin Stopa, Peter Winsor, Harper Simmons, Mary-Louise Timmermans, Yueng-Djern Lenn, Rob Pinkel, Laurie Padman, Ruth Musgrave, Joe Metzger, Caitlin Whalen, and Amy Waterhouse for scientific support and insight; and to Mike Gregg and Dave Winkel for supporting the transition of the MMP instrumentation from APL/UW to SIO. We sincerely appreciate the feedback we received from Ilker Fer and three anonymous reviewers, whose insightful comments and suggestions greatly improved this work.

Microstructure data are available for download at https:// microstructure.ucsd.edu. Mooring data are available from the authors upon request.

\section{APPENDIX}

\section{Slab Model}

The near-inertial mixed layer response to wind forcing can be modeled as a damped slab (Pollard and Millard 1970). Details of this model are described in D'Asaro (1985). In this analysis, the mixed layer depth $H$ is inferred from the ADCP velocity record to be $15 \mathrm{~m}$, while the artificial damping term $r=0.05 f$ is chosen to maximize correlation between the magnitude of slab model and observed velocities following Alford (2001). The model is initialized on August first with initial ocean velocity of zero, and forced using the NCEP reanalysis winds.

Comparing NCEP winds to measurements recorded at the NOAA ESRL Point Barrow station suggests that while the spectral slope of the reanalysis winds are generally similar to

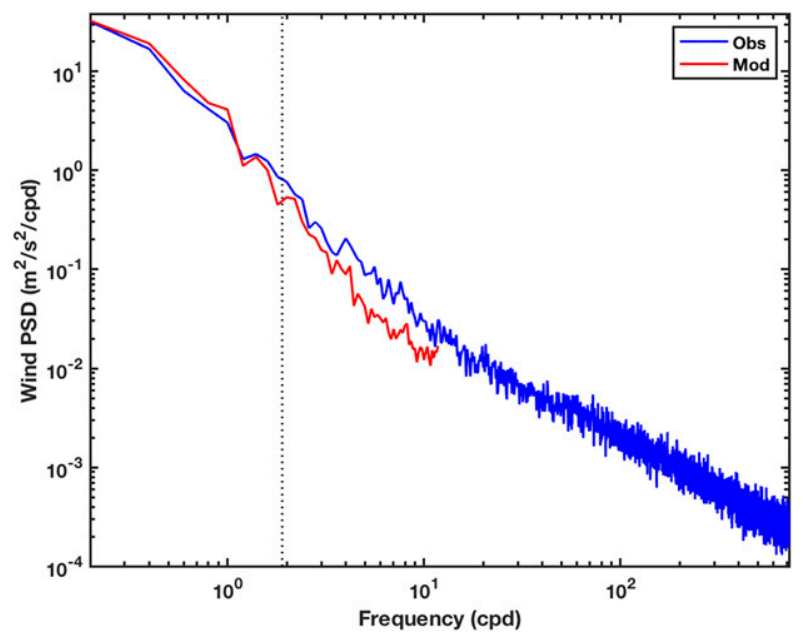

FIG. A1. Comparison of the reanalysis wind product (red) to observed winds at Point Barrow from 1 Aug through 30 Sep 2015. The local inertial frequency is indicated by a dashed black line; the reanalysis product has less variance by about a factor of 2 at this frequency.

observations, the reanalysis winds have lower variance around the inertial frequency by about a factor of 2 (Fig. A1).

The damping term $r$ represents all sources of dissipation within the mixed layer, including turbulent mixing at the boundary layer, radiation via internal waves, and deepening of the mixed layer. Many midlatitude studies use a value of $r=0.15 f$.

When running a slab model, a free parameter $r$ represents energy loss in the mixed layer due to local turbulence, the radiation of internal waves, or other processes. The parameter $r$ is constrained to be larger than 0 , and $r \ll f$ is required for stability. A second parameter $H_{\text {ref }}$, representing the reference depth of the mixed layer, is determined from observations. As we have mixed layer velocity measurements available, we use these to tune $r$ and $H$ by running through combinations within a range consistent with the observed mixed layer depth to optimize agreement between the magnitudes of the slab model velocities and the near-inertial filtered observations, initializing the model with zero velocity at the beginning of August 2015. We find that using $H=15 \mathrm{~m}$ and $r=0.05 f$ is consistent with the observed data $\left(R^{2}=0.7\right.$ with a 2 -h phase shift). This ratio of $r / f$ is 3 times lower than the frequently used $r=0.15 f$ (Alford 2001, 2003), and corresponds to a decay time scale of 10.5 days.

Using these parameters, we run the Pollard-Millard slab model and compare the results to the observed velocity (Fig. Microstructure mixing observations and finescale parameterizations in the Beaufort Sea). Over the large wind event from yearday 240 to 242 , the average wind stress is $0.1 \mathrm{~N} \mathrm{~m}^{-2}$ (Fig. A2a, standard deviation $5 \times 10^{-3} \mathrm{~N} \mathrm{~m}^{-2}$ ). From yearday 243 to 251 , mixed layer velocity observations from the uplooking $300 \mathrm{kHz}$ ADCP were available and agreed well with modeled velocities, building confidence that the reanalysis winds captured the same event observed by the mooring (Figs. A2b,c, ADCP observations shown as dashed lines). The average energy flux from the wind into the ocean between 


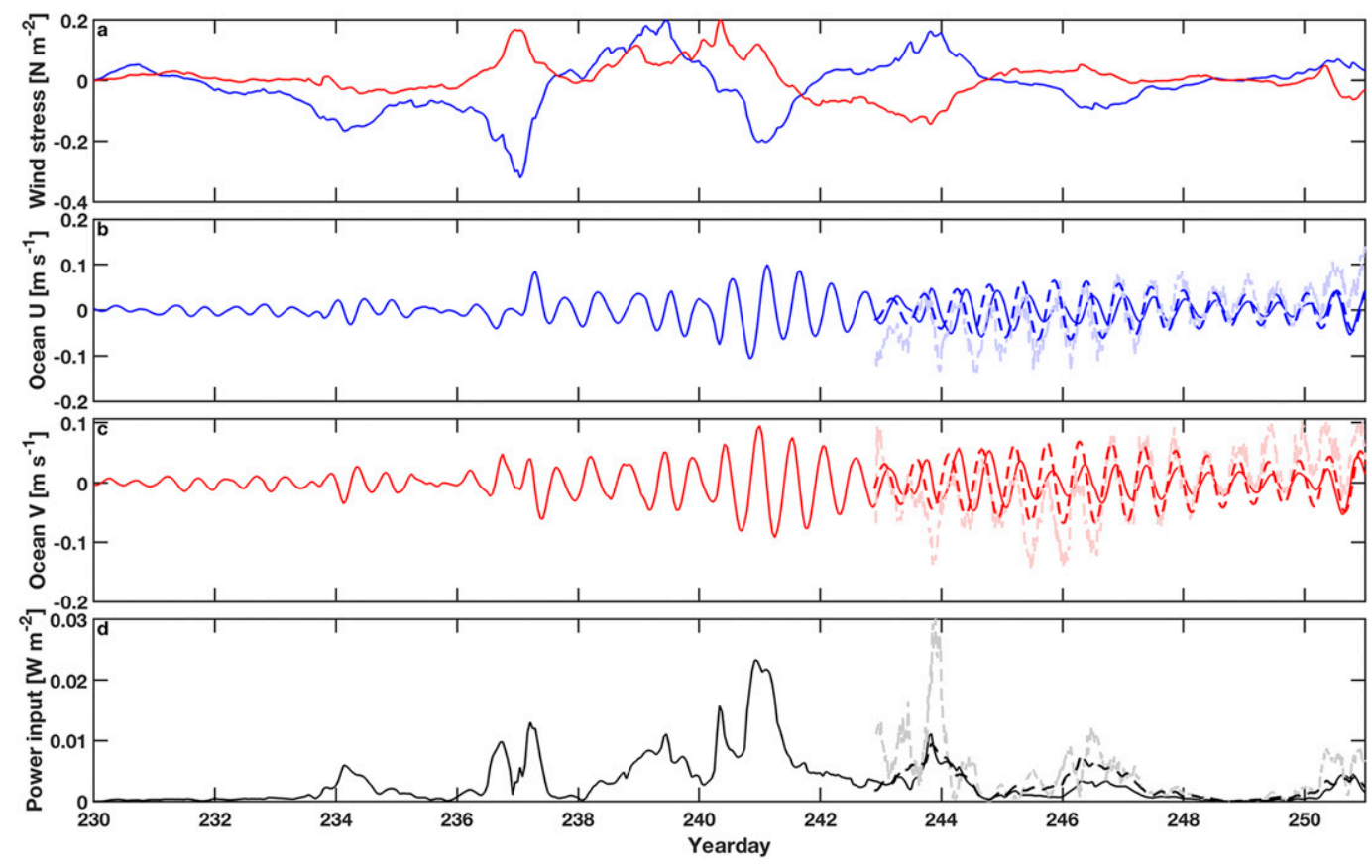

FIG. A2. (a) Wind stress input for slab model, based on CFSv2 10-m winds and assuming no initial ocean velocity. Blue and red represent east-west and north-south stress, respectively. (b) East-west mixed layer inertial velocity from slab model. Dashed line represents measured $15-\mathrm{m}$ velocity filtered at the near-inertial frequency. Light dashed line is the unfiltered 15-m velocity. (c) As in (b), but for north-south mixed layer velocity. (d) Power input from the slab model calculated as $\boldsymbol{\tau} \cdot \mathbf{u}$, in which $\mathbf{u}$ is inertial velocity from the slab model. The dashed line represents $\boldsymbol{\tau} \cdot \mathbf{u}_{\mathrm{obs}}$, where $\mathbf{u}_{\mathrm{obs}}$ is the observed $15-\mathrm{m}$ velocity filtered at the near-inertial frequency, and $\boldsymbol{\tau}$ is calculated from reanalysis winds. The light dashed line is the same calculation using the unfiltered $15-\mathrm{m}$ velocity.

yeardays 240-242 is estimated as $\boldsymbol{\tau} \cdot \mathbf{u}_{\text {slab }}=0.01 \mathrm{~W} \mathrm{~m}^{-2}$, in which $\boldsymbol{\tau}$ is the wind stress calculated from the reanalysis winds, and $\mathbf{u}_{\text {slab }}$ is the modeled near-inertial response (Fig. A2d, standard deviation $7 \times 10^{-3} \mathrm{~W} \mathrm{~m}^{-2}$ ).

The wind energy input into the ocean can also be estimated using the inertially filtered observed mixed layer velocities $\mathbf{u}_{\text {obs }}$ along with the reanalysis $\boldsymbol{\tau}$ to calculate $\boldsymbol{\tau} \cdot \mathbf{u}_{\text {obs. }}$. Observed velocities are only available starting on yearday 243 when the mooring was deployed. Using the CFSv2 winds with $\mathbf{u}_{\text {obs }}$, the average energy flux from yearday 243 to 247 is $4 \times 10^{-3} \mathrm{~W} \mathrm{~m}^{-2}$ (with standard deviation $2 \times 10^{-3} \mathrm{~W} \mathrm{~m}^{-2}$ ). Over the same yeardays, calculating energy flux using $\mathbf{u}_{\text {slab }}$ results in a smaller flux of $3 \times 10^{-3} \mathrm{~W} \mathrm{~m}^{-2}$ (with standard deviation $2 \times$ $10^{-3} \mathrm{~W} \mathrm{~m}^{-2}$ ). This suggests that the total wind energy input into the ocean may be larger than the slab model estimate, which is consistent with observed mixed layer velocities that are slightly larger than modeled velocities (Figs. A2b,c). Comparing CFSv2 winds for the Point Barrow region to measurements taken at Point Barrow suggests that the reanalysis winds have lower variance around the inertial frequency by about a factor of 2 . If the clockwise rotating inertial frequency component of the wind forcing at the mooring location is underestimated by the reanalysis product, using the reanalysis winds likely would result in an underestimation of the wind-to-ocean inertial energy flux by a similar factor. Thus we suspect our wind-energy flux may be biased low by up to a factor of 2 .
The slab model suggests that the wind event would have caused inertial oscillations at the two MMP survey sites. The modeled mean energy flux from the wind into the ocean from yeardays 240 to 242 is $6 \times 10^{-3} \mathrm{~W} \mathrm{~m}^{-2}$ at the MMP1 survey site and $5 \times 10^{-3} \mathrm{~W} \mathrm{~m}^{-2}$ at the MMP2 site.

\section{REFERENCES}

Aagaard, K., L. Coachman, and E. Carmack, 1981: On the halocline of the Arctic Ocean. Deep-Sea Res, 28A, 529-545, https:// doi.org/10.1016/0198-0149(81)90115-1.

Alford, M. H., 2001: Internal swell generation: The spatial distribution of energy flux from the wind to mixed-layer near-inertial motions. J. Phys. Oceanogr., 31, 2359-2368, https://doi.org/10.1175/1520-0485(2001)031<2359:ISGTSD> 2.0.CO;2.

— 2003 : Improved global maps and 54-year history of windwork on ocean inertial motions. Geophys. Res. Lett., 30, 14241427, https://doi.org/10.1029/2002GL016614.

_ 2010: Sustained, full-water-column observations of internal waves and mixing near Mendocino Escarpment. J. Phys. Oceanogr., 40, 2643-2660, https://doi.org/10.1175/2010JPO4502.1.

— shear, strain and microstructure at low latitude. J. Geophys. Res., 106, 16 947-16 968, https://doi.org/10.1029/2000JC000370.

Bebieva, Y., and M.-L. Timmermans, 2017: The relationship between double-diffusive intrusions and staircases in the Arctic Ocean. J. Phys. Oceanogr., 47, 867-878, https://doi.org/10.1175/JPO-D16-0265.1. 
Cairns, J. L., and G. O. Williams, 1976: Internal wave observations from a midwater float, 2. J. Geophys. Res., 81, 1943-1950, https://doi.org/10.1029/JC081i012p01943.

Chanona, M., 2020: Spatial and temporal variability of internal wave-driven mixing in the Arctic Ocean. Ph.D. thesis, University of British Columbia, 120 pp., https://doi.org/ 10.14288/1.0389888.

—_, and S. Waterman, 2020: Temporal variability of internal wave-driven mixing in two distinct regions of the Arctic Ocean. J. Geophys. Res. Oceans, 125, e2020JC016181, https:// doi.org/10.1029/2020JC016181.

- - — , and Y. Gratton, 2018: Variability of internal wavedriven mixing and stratification in Canadian Arctic shelf and shelf-slope waters. J. Geophys. Res. Oceans, 123, 9178-9195, https://doi.org/10.1029/2018JC014342.

Chinn, B. S., J. B. Girton, and M. H. Alford, 2016: The impact of observed variations in the shear-to-strain ratio of internal waves on inferred turbulent diffusivities. J. Phys. Oceanogr., 46, 3299-3320, https://doi.org/10.1175/JPO-D-15-0161.1.

Coachman, L., and C. Barnes, 1961: The contribution of Bering Sea water to the Arctic Ocean. Arctic, 14, 147-161, https://doi.org/ 10.14430/arctic3670.

Cole, S. T., J. M. Toole, L. Rainville, and C. M. Lee, 2018: Internal waves in the Arctic: Influence of ice concentration, ice roughness, and surface layer stratification. J. Geophys. Res. Oceans, 123, 5571-5586, https://doi.org/10.1029/2018JC014096.

D'Asaro, E., 1985: The energy flux from the wind to nearinertial motions in the mixed layer. J. Phys. Oceanogr., 15, 1043-1059, https://doi.org/10.1175/1520-0485(1985)015<1043: TEFFTW $>2.0 . \mathrm{CO}$; 2

Dosser, H. V., and L. Rainville, 2016: Dynamics of the changing near-inertial internal wave field in the Arctic Ocean. J. Phys. Oceanogr., 46, 395-415, https://doi.org/10.1175/ JPO-D-15-0056.1.

Fer, I., 2009: Weak vertical diffusion allows maintenance of cold halocline in the central Arctic. Atmos. Ocean. Sci. Lett., 2, 148152, https://doi.org/10.1080/16742834.2009.11446789.

- 2014: Near-inertial mixing in the central Arctic Ocean. J. Phys. Oceanogr., 44, 2031-2049, https://doi.org/10.1175/ JPO-D-13-0133.1.

Garrett, C., and W. Munk, 1972: Oceanic mixing by breaking internal waves. Deep-Sea Res., 19, 823-832, https://doi.org/ 10.1016/0011-7471(72)90001-0.

_ progress report. J. Geophys. Res., 80, 291-297, https://doi.org/ 10.1029/JC080i003p00291.

Gill, A. E., 1982: Atmosphere-Ocean Dynamics. Academic Press, $662 \mathrm{pp}$.

Gregg, M. C., 1989: Scaling turbulent dissipation in the thermocline. J. Geophys. Res., 94, 9686-9698, https://doi.org/10.1029/ JC094iC07p09686.

— 1999: Uncertainties and limitations in measuring $\varepsilon$ and $\chi_{T}$ J. Atmos. Oceanic Technol., 16, 1483-1490, https://doi.org/ 10.1175/1520-0426(1999)016<1483:UALIMA >2.0.CO;2.

— J. Geophys. Res., 96, 16 709-16 719, https://doi.org/10.1029/ 91JC01385.

_ T. B. Sanford, and D. P. Winkel, 2003: Reduced mixing from the breaking of internal waves in equatorial waters. Nature, 422, 513-515, https://doi.org/10.1038/nature01507.

_ E. D'Asaro, J. Riley, and E. Kunze, 2018: Mixing efficiency in the ocean. Annu. Rev. Mar. Sci., 10, 443-473, https://doi.org/ 10.1146/ANNUREV-MARINE-121916-063643.
Guthrie, J. D., J. H. Morison, and I. Fer, 2013: Revisiting internal waves and mixing in the Arctic Ocean. J. Geophys. Res. Oceans, 118, 3966-3977, https://doi.org/10.1002/jgrc.20294.

- I. Fer, and J. Morison, 2015: Observational validation of the diffusive convection flux laws in the Amundsen Basin, Arctic Ocean. J. Geophys. Res. Oceans, 120, 7880-7896, https:// doi.org/10.1002/2015JC010884.

Jackson, J. M., E. Carmack, F. McLaughlin, S. E. Allen, and R. Ingram, 2010: Identification, characterization, and change of the near-surface temperature maximum in the Canada Basin, 1993-2008. J. Geophys. Res., 115, C05021, https:// doi.org/10.1029/2009JC005265.

Klymak, J. M., R. Pinkel, and L. Rainville, 2008: Direct breaking of the internal tide near topography: Kaena Ridge, Hawaii. J. Phys. Oceanogr., 38, 380-399, https:// doi.org/10.1175/2007JPO3728.1.

Kunze, E., 2003: A review of oceanic salt-fingering theory. Prog. Oceanogr., 56, 399-417, https://doi.org/10.1016/S00796611(03)00027-2.

_- 2017: Internal-wave-driven mixing: Global geography and budgets. J. Phys. Oceanogr., 47, 1325-1345, https://doi.org/ 10.1175/JPO-D-16-0141.1.

— E. Firing, J. Hummon, T. K. Chereskin, and A. Thurnherr, 2006: Global abyssal mixing inferred from lowered ADCP shear and CTD strain profiles. J. Phys. Oceanogr., 36, 15531576, https://doi.org/10.1175/JPO2926.1.

Levine, M. D., C. A. Paulson, and J. H. Morison, 1985: Internal waves in the Arctic Ocean: Comparison with lower-latitude observations. J. Phys. Oceanogr., 15, 800-809, https://doi.org/ 10.1175/1520-0485(1985)015<0800:IWITAO>2.0.CO;2.

Lincoln, B. J., T. P. Rippeth, Y.-D. Lenn, M. L. Timmermans, W. J. Williams, and S. Bacon, 2016: Wind-driven mixing at intermediate depths in an ice-free Arctic Ocean. Geophys. Res. Lett., 43, 9749-9756, https://doi.org/10.1002/ 2016GL070454.

Lique, C., J. D. Guthrie, M. Steele, A. Proshutinsky, J. H. Morison, and R. Krishfield, 2014: Diffusive vertical heat flux in the Canada Basin of the Arctic Ocean inferred from moored instruments. J. Geophys. Res. Oceans, 119, 496-508, https:// doi.org/10.1002/2013JC009346.

Martin, T., M. Steele, and J. Zhang, 2014: Seasonality and longterm trend of Arctic Ocean surface stress in a model. J. Geophys. Res. Oceans, 119, 1723-1738, https://doi.org/ 10.1002/2013JC009425.

Martini, K. I., H. L. Simmons, C. A. Stoudt, and J. K. Hutchings, 2014: Near-inertial internal waves and sea ice in the Beaufort Sea. J. Phys. Oceanogr., 44, 2212-2234, https://doi.org/10.1175/ JPO-D-13-0160.1.

Maslanik, J., and J. Stroeve, 1999: Near-real-time DMSP SSMIS daily polar gridded sea ice concentrations, version 1 . NASA National Snow and Ice Data Center Distributed Active Archive Center, accessed 16 December 2019, https://doi.org/ 10.5067/U8C09DWVX9LM.

Morison, J. H., C. E. Long, and M. D. Levine, 1985: Internal wave dissipation under sea ice. J. Geophys. Res., 90, 11 959-11966, https://doi.org/10.1029/JC090IC06P11959.

Munk, W., and C. Wunsch, 1998: Abyssal recipes II: Energetics of tidal and wind mixing. Deep-Sea Res. I, 45, 1977-2010, https:// doi.org/10.1016/S0967-0637(98)00070-3.

Osborn, T. R., 1980: Estimates of the local rate of vertical diffusion from dissipation measurements. J. Phys. Oceanogr., 10, 83-89, https://doi.org/10.1175/1520-0485(1980)010<0083:EOTLRO> 2.0. $\mathrm{CO} ; 2$. 
Padman, L., and T. M. Dillon, 1987: Vertical heat fluxes through the Beaufort Sea thermohaline staircase. J. Geophys. Res., 92, 10 799-10 806, https://doi.org/10.1029/JC092iC10p10799.

— , and S. Erofeeva, 2004: A barotropic inverse tidal model for the Arctic Ocean. Geophys. Res. Lett., 31, L02303, https:// doi.org/10.1029/2003GL019003.

Pickart, R. S., T. J. Weingartner, L. J. Pratt, S. Zimmermann, and D. J. Torres, 2005: Flow of winter-transformed Pacific water into the western Arctic. Deep-Sea Res. II, 52, 3175-3198, https://doi.org/10.1016/j.dsr2.2005.10.009.

Pinkel, R., 2005: Near-inertial wave propagation in the western Artic. J. Phys. Oceanogr., 35, 645-665, https://doi.org/10.1175/ JPO2715.1.

Pollard, R. T., and R. C. Millard, 1970: Comparison between observed and simulated wind-generated inertial oscillations. Deep-Sea Res., 17, 153-175, https://doi.org/10.1016/ 0011-7471(70)90043-4.

Polzin, K. L., J. M. Toole, and R. W. Schmitt, 1995: Finescale parameterizations of turbulent dissipation. J. Phys. Oceanogr., 25, 306-328, https://doi.org/10.1175/1520-0485(1995)025<0306: FPOTD $>2.0 . \mathrm{CO} ; 2$.

— E. Kunze, J. Hummon, and E. Firing, 2002: The finescale response of lowered ADCP velocity profiles. J. Atmos. Oceanic Technol., 19, 205-224, https://doi.org/10.1175/15200426(2002)019<0205:TFROLA > 2.0.CO;2.

—, A. C. Naveira Garabato, T. N. Huussen, B. M. Sloyan, and S. Waterman, 2014: Finescale parameterizations of turbulent dissipation. J. Geophys. Res. Oceans, 119, 1383-1419, https:// doi.org/10.1002/2013JC008979.

Rainville, L., and P. Winsor, 2008: Mixing across the Arctic Ocean: Microstructure observations during the Beringia 2005 expedition. Geophys. Res. Lett., 35 L08606, https://doi.org/10.1029/ 2008GL033532.

— eration in the seasonally ice-free Arctic. Geophys. Res. Lett., 36, L23604, https://doi.org/10.1029/2009GL041291.

Rudels, B., E. P. Jones, U. Schauer, and P. Eriksson, 2004: Atlantic sources of the Arctic Ocean surface and halocline waters. Polar Res., 23, 181-208, https://doi.org/10.1111/j.17518369.2004.tb00007.x.

Saha, S., and Coauthors, 2010: The NCEP Climate Forecast System Reanalysis. Bull. Amer. Meteor. Soc., 91, 1015-1057, https:// doi.org/10.1175/2010BAMS3001.1.

Shaw, W., T. Stanton, M. McPhee, J. Morison, and D. Martinson, 2009: Role of the upper ocean in the energy budget of Arctic sea ice during SHEBA. J. Geophys. Res., 114, C06012, https:// doi.org/10.1029/2008JC004991.

Shibley, N. C., M.-L. Timmermans, J. R. Carpenter, and J. M. Toole, 2017: Spatial variability of the Arctic Ocean's double-diffusive staircase. J. Geophys. Res. Oceans, 122, 980-994, https://doi.org/ 10.1002/2016JC012419.

Smyth, W. D., and J. N. Moum, 2000: Anisotropy of turbulence in stably stratified mixing layers. Phys. Fluids, 12, 1343-1362, https://doi.org/10.1063/1.870386.

Stopa, J. E., F. Ardhuin, and F. Girard-Ardhuin, 2016: Wave climate in the Arctic 1992-2014: Seasonality and trends. Cryosphere, 10, 1605-1629, https://doi.org/10.5194/tc-10-1605-2016.

Timmermans, M.-L., J. Toole, A. Proshutinsky, R. Krishfield, and A. Plueddemann, 2008: Eddies in the Canada basin, Arctic Ocean, observed from ice-tethered profilers. J. Phys. Oceanogr., 38, 133-145, https://doi.org/10.1175/2007JPO3782.1.

_- , and Coauthors, 2014: Mechanisms of Pacific summer water variability in the Arctic's Central Canada basin. J. Geophys. Res. Oceans, 119, 7523-7548, https://doi.org/ 10.1002/2014JC010273.

- - J. Marshall, A. Proshutinsky, and J. Scott, 2017: Seasonally derived components of the Canada basin halocline. Geophys. Res. Lett., 44, 5008-5015, https://doi.org/10.1002/ 2017GL073042.

_ J. M. Toole, and R. A. Krishfield, 2018: Warming of the interior Arctic Ocean linked to sea ice losses at the basin margins. Sci. Adv., 4, 30167462, https://doi.org/10.1126/sciadv.aat6773.

Toole, J. M., M.-L. Timmermans, D. K. Perovich, R. A. Krishfield, A. Proshutinsky, and J. Richter-Menge, 2010: Influences of the ocean surface mixed layer and thermohaline stratification on Arctic sea ice in the central Canada Basin. J. Geophys. Res., 115, C10018, https://doi.org/10.1029/2009JC005660.

Waterhouse, A. F., and Coauthors, 2014: Global patterns of diapycnal mixing from measurements of the turbulent dissipation rate. J. Phys. Oceanogr., 44, 1854-1872, https://doi.org/10.1175/ JPO-D-13-0104.1.

Waterman, S., K. L. Polzin, A. C. Naveira Garabato, K. L. Sheen, and A. Forryan, 2014: Suppression of internal wave breaking in the Antarctic Circumpolar Current near topography. J. Phys. Oceanogr., 44, 1466-1492, https://doi.org/10.1175/ JPO-D-12-0154.1.

Whalen, C. B., L. D. Talley, and J. A. MacKinnon, 2012: Spatial and temporal variability of global ocean mixing inferred from Argo profiles. Geophys. Res. Lett., 39, L18612, https://doi.org/ 10.1029/2012GL053196.

— J. A. MacKinnon, L. D. Talley, and A. F. Waterhouse, 2015: Estimating the mean diapycnal mixing using a finescale strain parameterization. J. Phys. Oceanogr., 45, 1174-1188,https:// doi.org/10.1175/JPO-D-14-0167.1.

Winters, K. B., and E. A. D'Asaro, 1997: Direct simulation of internal wave energy transfer. J. Phys. Oceanogr., 27, 1937-1945, https://doi.org/10.1175/1520-0485(1997)027<1937:DSOIWE> 2.0.CO;2. 